\title{
Pd- $\mathrm{LaFeO}_{3}$ catalysts in aqueous ethanol: Pd reduction, leaching, and structural transformations in the presence of a base
}

\author{
Stefano Checchia, ${ }^{1,7}$ Christopher J. Mulligan, ${ }^{2}$ Hermann Emerich, ${ }^{3}$ Ivo Alxneit, ${ }^{4}$ Frank \\ Krumeich, ${ }^{5}$ Marco Di Michiel, ${ }^{1}$ Paul. B. J. Thompson, ${ }^{6}$ King Kuok (Mimi) Hii, ${ }^{2 *}$ Davide Ferri, ${ }^{4 *}$ \\ Mark A. Newton $5^{*}$ \\ ${ }^{1}$ ID15A, ESRF - The European Synchrotron, 71 Avenue Des Martyrs, F-38000 Grenoble, France. \\ ${ }^{2}$ Department of Chemistry, Imperial College London, Molecular Sciences Research Hub, 80, \\ Wood Lane, London W12 0BZ, UK. \\ 3 Swiss-Norwegian Beamlines (SNBL), ESRF - The European Synchrotron, 71 Avenue Des \\ Martyrs, F-38000 Grenoble, France. \\ ${ }^{4}$ Paul Scherrer Institut, CH-5232 Villigen, Switzerland. \\ ${ }^{5}$ ETH Zurich, Department of Chemistry and Applied Biosciences, Vladimir-Prelog Weg, 1-5/10, \\ 8093, Zurich, Switzerland. \\ ${ }^{6}$ XMaS UK CRG beamline, ESRF - The European Synchrotron, 71 Avenue Des Martyrs , F- \\ 38000 Grenoble, France. \\ ${ }^{7}$ Lund University, MAX-IV Laboratory, Fotongatan 2, SE-22100 Lund, Sweden.
}

*Corresponding authors:_manewton68@gmail.com; mimi.hii@imperial.ac.uk; davide.ferri@psi.ch

This document is the accepted manuscript version of the following article: Checchia, S., Mulligan, C. J., Emerich, H., Alxneit, I., Krumeich, F., Di Michiel, M., ... Newton, M. A. (2020). Pd-LaFeO3 catalysts in aqueous ethano1: Pd reduction, 1eaching, and structural transformations in the presence of a base. ACS Catalysis, 10(6), 3933-3944. https://doi.org/10.1021/acscata1.9b04869 


\begin{abstract}
The reactive behaviour of three catalysts based on $\mathrm{Pd}$-loaded $\mathrm{LaFeO}_{3}$ was investigated in terms of the reducibility of $\mathrm{Pd}$ and its propensity to leaching into the liquid phase in flowing solutions prototypical of C-C coupling catalysis in a continuous flow reactor cell. In situ QEXAFS spectroscopy showed that $\mathrm{Pd}$ remains stable and non-reducible in the flowing ethanol/water solvent mixture under heating to $353 \mathrm{~K}$. However, ex situ TEM, high energy X-ray diffraction (HXRD), and fluorescence yield Fe K-edge XANES show that the addition of a significant amount of base $\left(\mathrm{K}_{2} \mathrm{CO}_{3}, 0.1 \mathrm{M}\right)$ results in the structural degradation of the perovskite support as well as the mobilization of Pd along the sample bed that is dependent on the structure and crystallite size of the perovskite. The results are discussed in terms of the use of perovskite-type oxides in various areas of research where they are placed in contact with liquid phases of variable temperature and elevated $\mathrm{pH}$.
\end{abstract}

Keywords: palladium catalysis, leaching, Suzuki coupling, basic condition X-ray absorption spectroscopy, X-ray diffraction, pair distribution function, 


\section{Introduction}

Perovskite-type oxides are a versatile class of materials of generic composition $\mathrm{ABO}_{3}$ offering endless possibilities for combining different elements at the 12-coordinated A-site and the 6-coordinated B-site. The many fold properties that result ${ }^{1}$ have led to perovskites being applied in a wide range of areas, among which catalysis, ${ }^{2}$ electrochemistry, ${ }^{3}$ and photon driven processes ${ }^{4}$ for energy and chemicals production. In many of these applications the perovskite interacts with a liquid solvent phase and numerous other compounds that may necessitate operation in a basic environment. 5,6

Pd-substituted $\mathrm{LaFeO}_{3}$ perovskite oxides ${ }^{7}$ - along with their $\mathrm{Rh}$ and $\mathrm{Pt}$ analogues - have been found to have distinct structural-reactive properties ("self-regeneration") under redox cycling conditions prototypical of those that occur in modern petrol engine operation. It was found that Pd substituted for Fe into the perovskite B site could be reversibly segregated to the surface of the support to form small metallic Pd nanoparticles during the reducing phase of operation. When feed conditions were switched to oxidising they could be rapidly oxidized and $\mathrm{Pd}^{3+}$ reincorporated at its original site. The net result was a catalyst system that was far more resistant to sintering of the Pd phase into larger and much less active Pd particles than was the case for more traditionally supported Pd catalysts. The ability to dynamically adapt to their environment led to the description as "intelligent" catalysts. ${ }^{7}$

Later work further showed that a range of $\mathrm{Pd}$ substituted $\mathrm{LaFeO}_{3}$ or $\mathrm{LaCoO}_{3}$ could also be effectively used in the completely different situation of C-C coupling processes, such as the Heck, ${ }^{8}$ Suzuki, ${ }^{9}$ and Sonogashira ${ }^{10}$ reactions. A summary of these studies and the mechanistic conclusions derived from them is given schematically in Figure 1. The oxidized perovskite, for which much previous study had shown to be comprised of Pd substituted for a fraction of the B- 
site Fe was exposed to a proto-typical Suzuki coupling reaction mixture, using aqueous isopropyl alcohol (IPA) as a solvent. Under relative mild temperatures (333 K), the ability of the materials to catalyse the desired coupling reaction was then assessed using a batch reactor and post factum microscopy and X-ray diffraction. These studies concluded that the role of the perovskites was to provide a reservoir of $\mathrm{Pd}$, an active fraction of which was lost to the liquid phase under conditions of catalysis. It was further concluded that solubilised Pd was responsible for the high levels of catalytic activity observed in reactions conducted within a "batch" reactor. Post reaction analyses indicated that the levels of $\mathrm{Pd}$ that existed in the reaction liquor was of the order of $2 \mathrm{ppm}$ and that, therefore, the solubilised $\mathrm{Pd}$ was effectively redeposited onto the perovskite support after reaction. At no point in these works was any evidence presented for the formation of Pd black or Pd nanoparticles, either in solution or on the perovskite itself.

The mechanism of Pd solubilisation was, however, not understood. It was postulated ${ }^{8}$ that under these Suzuki coupling conditions the solvent (50:50 IPA/water) may initially reduce the Pd contained within the perovskite such that Pd may then be present at the surface of the catalyst. Once at the surface the Pd could then react with the halogens present in the mixture to form soluble $\operatorname{PdX}(\mathrm{X}=\mathrm{Cl}, \mathrm{Br})$ organometallic compounds (halogens being most commonly implicated in the leaching of atom $\mathrm{Pd}$ from supported catalysts). Using post factum transmission electron microscopy (TEM), it was also noted that in facilitating the Suzuki reaction the perovskite had undergone "a profound morphological change". XRD indicated that the catalyst was no longer the starting perovskite and that neither lanthanum oxide, nor lanthanum hydroxide were present. The detailed reasons behind the structural changes the perovskite had undergone were not elucidated. ${ }^{8}$ The conditions required for C-C coupling reactions add to the difficulty of understanding structural changes in a batch reactor. Typically, the catalyst is placed in contact not only with the 
substrate molecules (e. g. 4-bromo anisole), but also with an acid (e.g. phenyl boronic acid), an excess of base $\left(\mathrm{K}_{2} \mathrm{CO}_{3}\right)$, and an aqueous solvent (1:1 isoproyl alcohol/water). ${ }^{8}$ Comprehending the nature of the active species and what mechanisms lead to Pd solubilisation within such a complex reaction mixture is, therefore, not trivial, as a copious literature attests to. ${ }^{12-20}$

Heterogenization of C-C coupling catalysis, despite its potential advantages, has been persistently stymied by the leaching of Pd into the solution phase. ${ }^{12-20}$ This issue makes it necessary to separate the leached Pd from the reaction products. Whilst such separations can be relatively easily achieved, this adds processes of purification and palladium recovery that would otherwise not be required, which add unfavourably to the cost of the overall process; and product controls within the pharmaceutical industry, specifically with regards to heavy metal residues, are necessarily stringent. As a result, large scale utilisation of the unique properties of Pd in facilitating important chemical conversions has not been forthcoming.

The use of continuous flow, rather than batch, presents many potential benefits to large scale catalytic synthetic chemistry, not least of which safety, ${ }^{26}$ and has recently become an intensively researched field. ${ }^{27-34}$ Flow reactors are also appealing in the study of more fundamental aspects of both homogeneous and heterogeneous catalysis. Continuous flow arrangements provide well defined time lines for the interrogation of reaction kinetics, ${ }^{35}$ and allow the catalysts to be studied in a spatial manner - axially, along the catalyst bed - in the direction of the flow. A continuous flow approach, when coupled to suitable time and spatially resolving probes, also permits observation of any gradients (be they in Pd phase, average particle size, or Pd concentration) that might arise as a result of the fundamental chemistry at work in a system in a clearer and less ambiguous manner. Any potential transport of the Pd along the catalyst bed can 
therefore be probed by such an arrangement. Thus, insight into the behaviour of catalytic systems can be obtained that goes beyond that of a batch approach.

We have, therefore, started to deconstruct these types of catalytic reaction mixture within the paradigm of a single pass plug flow reactor, ${ }^{21-25}$ in an attempt to understand the effects of the individual components on the nature and mobility of the Pd present in a range of oxide-supported C-C coupling catalyst systems. Using this approach we have shown that aqueous ethanol can react with supported $\mathrm{Pd}$ by reducing surface $\mathrm{PdO}$, to yield supported $\mathrm{PdH}_{\mathrm{x}}$ nanoparticles at a rate highly dependent on the particle size of the starting PdO phase. ${ }^{21,22}$ It can then elicit agglomeration of $\mathrm{Pd}^{0}$ nanoparticles, thus negating the benefits of an initially high $\mathrm{Pd}$ dispersion. ${ }^{23}$

In this report we turn our attention to the behaviour of $\mathrm{Pd} / \mathrm{LaFeO}_{3}$ catalysts that, in terms of previously determined turnover numbers, ${ }^{8,9}$ are highly reactive (and also selective) catalysts for C-C coupling reactions. We show that exposure of these materials to aqueous ethanol does not lead to any reduction or dissolution of the $\mathrm{Pd}$ they contain. However, as soon as $0.1 \mathrm{M} \mathrm{K}_{2} \mathrm{CO}_{3}$ is introduced to the reaction mixture, reduced $\mathrm{Pd}$ starts to form at around $353 \mathrm{~K}$ and high levels of Pd leaching are then induced. The two processes, reduction and leaching of Pd, are found to be dependent on the crystallite size, the long-range structure of the $\mathrm{Pd} / \mathrm{LaFeO}_{3}$ catalysts, and also on whether the Pd has been incorporated within, or deposited on the perovskite.

\section{Experimental details}

2.1 Materials. Three Pd-loaded $\mathrm{LaFeO}_{3}$ catalyst samples of different origin were used in this study: two samples of stoichiometry $\mathrm{LaFe}_{0.95} \mathrm{Pd}_{0.05} \mathrm{O}_{3}$ made at PSI, analogous the those previously documented, ${ }^{34}$ and one of stoichiometry $\mathrm{LaFe}_{0.9} \mathrm{Pd}_{0.1} \mathrm{O}_{3}$ (Daihatsu commercial catalyst) 

36

In the first material (denoted as $\mathrm{LaFe}_{0.95} \mathrm{Pd}_{0.05} \mathrm{O}_{3}$ ) $\mathrm{Pd}$ was incorporated (from a $\mathrm{Pd}\left(\mathrm{NO}_{3}\right)_{2} \cdot 2 \mathrm{H}_{2} \mathrm{O}$ precursor) during the synthesis of the perovskite support. In the second sample (denoted as $\mathrm{Pd} @ \mathrm{LaFeO}_{3}$ ) Pd was deposited by wet impregnation (to a nominal 2 wt\% loading), onto the preformed $\mathrm{LaFeO}_{3}$ oxide $34 \mathrm{~b}, 34 \mathrm{c}$.

The specific surface area of the samples was measured at the temperature of liquid nitrogen using a Quantachrome Autosorb-1 instrument. Prior to the measurement, the sample was evacuated at $200^{\circ} \mathrm{C}$ for $1 \mathrm{~h}$.

2.2 X-ray absorption spectroscopy. Quick extended X-ray absorption fine structure (QEXAFS) experiments at the Pd K-edge were carried out in transmission geometry at BM31 of the Swiss-Norwegian beamlines at the ESRF using a Si (111) monochromator and ion chambers for the measurement of the beam reference, sample, and energy reference (a Pd foil). QEXAFS spectra were collected every 30-45 seconds. The beam size used was ca $0.5 \mathrm{~mm}(\mathrm{~V}) \times 3 \mathrm{~mm}$ (v).

Samples (ca. $75 \mathrm{mg}$, sieved to a 100-150 $\mu \mathrm{m}$ fraction) were loaded into the cell described by Chiarello et al. ${ }^{38,39}$ designed for operando measurements of working heterogeneous catalysts in a gas-solid environment. In the current case Teflon windows and seals were used for operation using flowing liquids. The $5 \mathrm{~mm}$ long bed was held in place between quartz wool plugs. The reactor was moved stepwise downwards at $0.5 \mathrm{~mm}$ intervals using a high precision $\mathrm{x}-\mathrm{y}-\mathrm{z}$ motor; once one scan of the sample was finished, the reactor was moved all the way upwards to start a new mapping from inlet to outlet. QEXAFS spectra were collected every 30-45 s. EXAFS maps of the catalyst beds where therefore collected in 5-7 min. 
Once loaded, a sample was mapped using Pd K-edge EXAFS in its dry state before being made wet at room temperature by flowing an ethanol/water mixture $(\mathrm{pH}=6.3)$ through it using a syringe driver at a rate of $0.1 \mathrm{mLmin}^{-1}$. Prior to loading into the syringe the solvents were individually degassed using flowing $\mathrm{N}_{2}$ and then sonicated before being mixed as required. Where used, $\mathrm{K}_{2} \mathrm{CO}_{3}$ was then added to $0.1 \mathrm{M}$ concentration, resulting in a solution $\mathrm{pH}$ of 12.9 .

Once in a wetted state at ambient temperature the sample was mapped again and then heated under a flow of the solvent to $353 \mathrm{~K}$ at $1 \mathrm{Kmin}^{-1}$, where it was then held. During this process the sample bed was continuously mapped (one full map collected every 5-8 min, i.e. every 5-8K from inlet to outlet using QEXAFS.

Fe K-edge and $\mathrm{Pd} \mathrm{L}_{3}$-edge X-ray absorption near edge structure (XANES) spectra of fresh and used samples were measured at the beamline XMaS (UK CRG) at ESRF using a Si (111) monochromator, a Ketek Si diode detector, and an in-vacuum sample changer described in ref. 40.

2.3 High-energy X-ray diffraction (HXRD). X-ray powder diffraction data were collected at the ID15A beamline ${ }^{53}$ at the European Synchrotron Radiation Facility synchrotron (ESRF). Powder samples were loaded into $1.5 \mathrm{~mm}$-diameter polyimide tubes and mounted at 500 mm distance from the detector (Dectris Pilatus 3X CdTe 2M). The X-ray wavelength was 0.1672 Å. Diffraction images were collected over $10 \mathrm{~s}$ for each catalyst sample and for polycrystalline $\mathrm{CeO}_{2}$ (NIST 674b). Background scattering of air and polyimide tube was measured for $100 \mathrm{~s}$.

2.4 Electron microscopy. Transmission Eelectron Microscopy (TEM) measurements were carried out using a Jeol 2010 transmission electron microscope with a $\mathrm{LaB}_{6}$ cathode operated 
at $200 \mathrm{KeV}$. Samples were prepared on holey carbon films or copper grids from sonicated suspensions in isopropanol.

Scanning Transmission electron microscopy (STEM) images were recorded on an aberration-corrected HD2700CS (Hitachi) operated at $200 \mathrm{kV}$ (cold field emitter). For the investigation, the material was dispersed in ethanol and a few drops of the suspension were deposited onto a perforated carbon foil supported on a copper grid. The grid was mounted on the single tilt holder of the microscope after evaporation of the ethanol. The probe corrector (CEOS), which is incorporated in the microscope column between the condenser lens and the probe-forming objective lens, provides a finely focussed beam resulting in a resolution better than $0.1 \mathrm{~nm}$. Different detectors were selected for imaging: (i) the high-angle annular dark field detector (HAADF) collects incoherently scattered electrons resulting in an intensity that strongly increases with the atomic number (Z-contrast). (ii) A special bright field detector allows to record phasecontrast images. (iii) A secondary electron detector installed inside the microscope column above the sample gives information about the sample morphology. Images $(1024 \times 1024$ pixels $)$ were recorded with frame times between 10 and 20 s. Analytical investigations were done with an energy-dispersive X-ray spectrometer (EDXS, EDAX) attached to the microscope column.

2.5 Infrared spectroscopy. Attenuated total reflection infrared (ATR-IR) spectra of the samples before and after the synchrotron experiments were acquired with a Platinum ATR unit (Bruker) installed within the sample compartment of a Vertex70 spectrometer (Bruker) using a DTGS detector by averaging 100 scans at $10 \mathrm{kHz}$ and at $4 \mathrm{~cm}^{-1}$ resolution. For comparison, a spectrum of solid $\mathrm{K}_{2} \mathrm{CO}_{3}$ was also collected. 
2.6 Data analysis. EXAFS data was processed using PAXAS ${ }^{41}$ and/or Prestopronto ${ }^{42}$ prior to analysis using EXCURV. ${ }^{43}$

HXRD images were scaled by the incident X-ray flux and subtracted by the background scattering of air and polyimide. Data correction and radial integration used the libraries FabIO $^{45}$ and pyFAI ${ }^{44}$. Rietveld analysis of the diffraction patterns was carried out using the program Topas v.5 (Bruker AXS). Patterns were truncated at $Q<13 \AA^{-1}$; background was fitted by Chebyshev polynomials; line profile was reproduced by pseudo-Voigt peaks, which allowed estimating crystallite size through the peak integral breadth according to the method described by Balzar et al. ${ }^{52}$ The real-space Pair Distribution Function (PDF), indicated herein as $G(r)$, was calculated as defined in eq. 43 in ref. ${ }^{46}$ using the program PDFgetX $3^{47}$ with a maximum value of momentum transfer of $Q_{\max }=20 \AA^{-1}$. Structural models were fitted to the PDF using the program PDFGui. ${ }^{47}$ PDF was modelled using "box-car" refinements ${ }^{51}$ and the $P b n m$ perovskite phase in successive 20 $\AA$ spans of real space up to $330-350 \AA$. The analogue refinement of standard $\mathrm{CeO}_{2}$ powder accounted for the intrinsic instrument-resolution-related decay, as its PDF intensity should not contain any effect due to crystallite size in the diffraction geometry used.

3. Results and discussion

3.1 Starting $\mathrm{LaFeO}_{3}$ and $\mathrm{Pd} / \mathrm{LaFeO}_{3}$ materials

3.1.1 HXRD characterisation: Rietveld analysis and PDF

Figures 2 (a-d) show the high energy X-ray diffraction (HXRD) patterns of the starting materials along with their respective Rietveld fits and residuals. Figure 3 shows the corresponding atomic pair distribution function (PDF) obtained from the same measurements. 
All these samples have the expected orthorhombic $\mathrm{LaFeO}_{3}$ perovskite structure, with space group Pbnm (\#62) and cell parameters $a \approx a_{\mathrm{c}} \sqrt{ } 2, b \approx a_{\mathrm{c}} \sqrt{ } 2, c \approx 2 a_{\mathrm{c}}$, where the subscript denotes the parent cubic unit cell. A schematic representation of this structure is given as Figure 4 and the detail of the structural parameters and phase composition derived for these materials, including undoped $\mathrm{LaFeO}_{3}$, are given in the Supporting Information (Tables S1 - S6).

The orthorhombic perovskite structure of these samples is also apparent in the short-range atomic arrangement shown by the PDF, as each curve is correctly fitted by a Pbnm structural model (Figure 3(b)). The fresh $\mathrm{LaFe}_{0.9} \mathrm{Pd}_{0.1} \mathrm{O}_{3}$ sample $\left(4.5 \mathrm{~m}^{2} / \mathrm{g}\right.$ ) is composed by $93 \%$ (by weight) Pbnm perovskite, $3.5 \% \mathrm{La}_{2} \mathrm{O}_{3}\left(P 6_{3} / m m c\right)$ and $3.5 \% \mathrm{Fe}_{2} \mathrm{O}_{3}(R-3 c)$. No secondary phases were detected in $\mathrm{Pd} @ \mathrm{LaFeO}_{3}\left(13 \mathrm{~m}^{2} / \mathrm{g}\right)$ and $\mathrm{LaFe}_{0.95} \mathrm{Pd}_{0.05} \mathrm{O}_{3}\left(14 \mathrm{~m}^{2} / \mathrm{g}\right)$. There are differences between the three $\mathrm{Pd}-$ loaded samples concerning the average crystallite size of the perovskite phase and its orthorhombic distortion, in terms of both cell parameters and $\mathrm{BO}_{6}$ octahedra tilt angles.

Analysis of peak broadening indicates an average crystallite size of $28( \pm 2) \mathrm{nm}$ for LeFe ${ }_{0.9} \mathrm{Pd}_{0.1} \mathrm{O}_{3}$, while the visibly less crystalline $\mathrm{Pd} @ \mathrm{LaFeO}_{3}$ and $\mathrm{LaFe}_{0.95} \mathrm{Pd}_{0.05} \mathrm{O}_{3}$ samples were estimated at $15( \pm 2)$ and $8( \pm 1) \mathrm{nm}$, respectively. The difference in crystallite size reflects the different values of specific surface area of the materials and is also evidenced by the amplitude of the pair distribution function (PDF), which decays faster (i.e. at lower $r$ ) for the latter two than for the more crystalline $\mathrm{LaFe}_{0.9} \mathrm{Pd}_{0.1} \mathrm{O}_{3}$ (Figure 3 ). The PDF amplitude is damped by an instrumentalresolution contribution, which is the same for all samples, and by the loss of structural coherence, which reflects the average crystallite size. While a marked difference between the two Pdsubstituted samples was anticipated in view of the harder sintering of $\mathrm{LaFe}_{0.9} \mathrm{Pd}_{0.1} \mathrm{O}_{3},{ }^{7,34}$ the comparatively high surface area of $\mathrm{Pd} @ \mathrm{LaFeO}_{3}$ reflects the more porous morphology resulting from a wet impregnation synthesis route. 
Partial substitution of the $\mathrm{Fe}^{3+}$ ion by the larger $\mathrm{Pd}^{3+}$ ion results in an increased octahedral tilt angle about the diad axis $\left(\varphi_{\mathrm{x}}\right)$, as expected from a reduced Goldschmidt ratio (Table S1). While the $\varphi_{\mathrm{x}}$ value of $11.1( \pm 0.3)^{\circ}$ in $\mathrm{Pd} @ \mathrm{LaFeO}_{3}$ (Table $\left.\mathrm{S} 1(\mathrm{~d})\right)$ is closest to the one found in undoped $\mathrm{LaFeO}_{3}$, suggesting little $\mathrm{Fe} / \mathrm{Pd}$ substitution in the bulk lattice, the tilt angle increases to 12.2( $( \pm 0.6)^{\circ}$ and $14.5( \pm 0.6)^{\circ}$ in $\mathrm{LaFe}_{0.95} \mathrm{Pd}_{0.05} \mathrm{O}_{3}$ and $\mathrm{LaFe}_{0.9} \mathrm{Pd}_{0.1} \mathrm{O}_{3}$, respectively (see Tables S1(c)). The Pd-loaded samples also differ in the orthorhombic distortion of the unit cell. The cell of $\mathrm{LaFe}_{0.95} \mathrm{Pd}_{0.05} \mathrm{O}_{3}$ is elongated along $a$ (corresponding to $c$ in the cubic setting), resulting in an increased orthorhombic strain with respect to undoped $\mathrm{LaFeO}_{3}$. Conversely, the cell of $\mathrm{LaFe}_{0.9} \mathrm{Pd}_{0.1} \mathrm{O}_{3}$ is very close to cubic, as cell expansion is confined to the $b c$ plane ( $a b$ in the cubic setting). Consequently, the $\mathrm{BO}_{6}$ octahedra are less elongated than in $\mathrm{LaFe}_{0.95} \mathrm{Pd}_{0.05} \mathrm{O}_{3}$. Again, $\mathrm{Pd} @ \mathrm{LaFeO}_{3}$ deviates the least from undoped $\mathrm{LaFeO}_{3}$. The respective $(a \sqrt{2}-c) /(a \sqrt{ } 2+c)$ ratios are $0.488 \%, 0.022 \%$, and $0.303 \%$, compared with $0.190 \%$ in $\mathrm{LaFeO}_{3}$.

\subsubsection{Pd K-edge EXAFS}

Pd K-edge EXAFS from the three samples measured in their dry state are shown as $\mathrm{k}^{3}$ weighted EXAFS (Figure 5(a)) and respective Fourier transforms (Figure 5(b)). Results of the fitting of these data using EXCURV ${ }^{41}$ are given in Table 1.

The Pd K-edge EXAFS (Figure 5) of $\mathrm{LaFe}_{0.9} \mathrm{Pd}_{0.1} \mathrm{O}_{3}$ is dominated by two scattering features (Pd-O at ca. $2 \AA$, and Pd-Fe at ca. $3.7 \AA$ ) that we would expect from Pd occupying a highly symmetric octahedral site predominantly surrounded in the second scattering shell by Fe atoms.

The scattering environment of the Pd for both $\mathrm{LaFe}_{0.95} \mathrm{Pd}_{0.05} \mathrm{O}_{3}$ and $\mathrm{Pd} @ \mathrm{LaFeO}_{3}$ is decidedly more complex (Figure 5(b)). In the $\mathrm{LaFe}_{0.95} \mathrm{Pd}_{0.05} \mathrm{O}_{3}$ case we infer a contribution of surface Pd, as evidenced from the short $\mathrm{r}_{\mathrm{Pd}-\mathrm{Fe}}$ interaction at $2.9 \AA$, to the overall EXAFS envelope 


\subsection{Behaviour in ethanol/water solvent flows with and without $\mathrm{K}_{2} \mathrm{CO}_{3}$}

Figure 6(a-d) shows Pd K-edge XANES spectra of $\mathrm{LaFe}_{0.9} \mathrm{Pd}_{0.1} \mathrm{O}_{3}$ obtained during heating under flows of 1:1 EtOH/ $\mathrm{H}_{2} \mathrm{O}$ in the absence, or in the presence of, $0.1 \mathrm{M} \mathrm{K}_{2} \mathrm{CO}_{3}$ (as indicated) and compares the behaviour observed at the reactor inlet with that observed at the reactor outlet.

In the absence of $\mathrm{K}_{2} \mathrm{CO}_{3}$ (Figure 6(a)) only small changes are observed as a result of heating in the ethanol/water mixture. The observed variation in the magnitude of the edge jump of the Pd K-edge is no more than $2 \%$ in each case. We associate the development of a small, lower binding energy shoulder to the Pd K-edge at ca. $23348 \mathrm{eV}$ with hydroxylation of the Pd at the surface of the material. An almost identical series of spectra is observed at the outlet under these conditions (Figure 6(c)). 
In the presence of $\mathrm{K}_{2} \mathrm{CO}_{3}$ a very different picture emerges (Figure 6(b)). As the temperature approaches $353 \mathrm{~K}$, a shift to lower energy in the Pd K-edge edge energy and a distinct change in the shape of the XANES occur that are indicative of the reduction of the Pd from a $\mathrm{Pd}^{3+}$ to $\mathrm{Pd}^{0}$ state, and formation of $\mathrm{Pd}$ nanoparticles. The addition of the base, therefore, induces a reduction of $\mathrm{Pd}$ to metal nanoparticles that the solvent alone, at least on these time/temperature scales, does not.

Secondly, reduction, is accompanied by changes in the absolute magnitude of the Pd Kedge and, therefore, in the concentration of Pd present along the sample bed. A considerable diminution of the edge jump, of up to ca. $40 \%$, is seen to occur at the reactor inlet. Conversely, we observe an augmentation of the edge jump (by ca. 10\%) at the outlet (Figure 6(d)) and the same changes in the shape of XANES as soon at temperatures above $353 \mathrm{~K}$. In other words, besides reduction of the Pd held within the perovskite-type structure, the presence of $\mathrm{K}_{2} \mathrm{CO}_{3}$ elicits a mobilisation of the Pd, some of which is then re-deposited toward the outlet of the bed in the direction of the flow.

Figure 7 summarises the axial changes in Pd K-edge jump observed during the exposure of the three catalysts used in this study to ethanol/water $/ \mathrm{K}_{2} \mathrm{CO}_{3}$ : (a) the commercial $\mathrm{LaFe}_{0.9} \mathrm{Pd}_{0.1} \mathrm{O}_{3}$ sample; (b) the $\mathrm{LaFe}_{0.95} \mathrm{Pd}_{0.05} \mathrm{O}_{3}$ sample; and, (c) the stoichiometrically equivalent $\mathrm{Pd} @ \mathrm{LaFeO}_{3}$ case. The $\mathrm{x}$-axis (map number) represents the time/temperature history of the sample as it is wetted and then heated. Map number 7 is the point at which the target temperature $(353 \mathrm{~K})$ was reached. In each case, the Pd K-edge jump for each axial position in the bed has been normalised to the respective values in the initial "wet" maps (made at ambient temperature under the solvent flow).

In the two materials where $\mathrm{Pd}$ has been incorporated into the $\mathrm{LaFeO}_{3}$ through substitution of a portion of $\mathrm{Fe}, \mathrm{LaFe}_{0.9} \mathrm{Pd}_{0.1} \mathrm{O}_{3}$ (Figure 7(a)) and $\mathrm{LaFe}_{0.95} \mathrm{Pd}_{0.05} \mathrm{O}_{3}$ (Figure 7(b)), a variation of 
the edge jump is observed. Hence, as indicated by the XANES data reported in Figure 6, once a temperature of $353 \mathrm{~K}$ has been achieved, Pd starts reduce and some of it is then leached into the solvent flow. The rates and extent of both reduction and movement of $\mathrm{Pd}$ in $\mathrm{LaFe}_{0.9} \mathrm{Pd}_{0.1} \mathrm{O}_{3}$ and $\mathrm{LaFe}_{0.95} \mathrm{Pd}_{0.05} \mathrm{O}_{3}$ are also radically different. In $\mathrm{LaFe}_{0.9} \mathrm{Pd}_{0.1} \mathrm{O}_{3}$, the level of $\mathrm{Pd}$ removed at the front end of the bed reaches in excess of $40 \%$ at the end of the experiment (Figure 7(a) and Figure 6(b)), whereas in $\mathrm{LaFe}_{0.95} \mathrm{Pd}_{0.05} \mathrm{O}_{3}$ only a $25-30 \%$ loss of $\mathrm{Pd}$ in the inlet is observed (Figure 7(b)) even over a slightly longer time period (16 rather than 14 sequential maps of the catalyst beds). In the case of Pd deposited upon the perovskite-type oxide $\left(\mathrm{Pd} @ \mathrm{LaFeO}_{3}\right)$, no reduction (evidenced by XANES) or mobilization (evidenced from the edge jump) of the $\mathrm{Pd}$ is observed and, concomitantly, no evidence of the leaching of the Pd in this sample is forthcoming. The three catalysts therefore behave very differently in the presence of the ethanol/water flow to which $\mathrm{K}_{2} \mathrm{CO}_{3}$ has been added.

From the knowledge of the total sample mass contained within the bed and the volume sampled by the X-rays at any given point within it, we can estimate the rate of Pd mobilisation. In the structurally most ordered of these perovskites (i.e. $\mathrm{LaFe}_{0.9} \mathrm{Pd}_{0.1} \mathrm{O}_{3}$ ), where this process is most severe, Pd is lost from the inlet of the bed with a time averaged rate of the order of ca. $2.5 \times 10^{14}$ Pd atoms s ${ }^{-1}$. For the $\mathrm{LaFe}_{0.95} \mathrm{Pd}_{0.05} \mathrm{O}_{3}$ sample, the rate of $\mathrm{Pd}$ loss is estimated to be over an order of magnitude lower (ca. $2 \times 10^{13} \mathrm{Pd}$ atoms s $\mathrm{s}^{-1}$ ).

If we further consider the turnover numbers achieved in ref. 8 for the coupling of 4bromoanisole $(53.5 \mathrm{mmol})$ using $2 \mu \mathrm{mol}$ of a very similar catalyst $\left(\mathrm{LaFe}_{0.95} \mathrm{Pd}_{0.05} \mathrm{O}_{3}\right)$ at $353 \mathrm{~K}$, and we assume that this sample leached Pd to the same degree as ours under reaction conditions, then, we can account to within a factor ca. 2 for the extent of the reaction observed in ref. 8 without invoking any role of the halogenated reactants used in this process. We come to this conclusion by 
calculating the amount of $\mathrm{Pd}$ leached into the reaction liquor at $353 \mathrm{~K}(60 \%)$ and multiply this by the calculated turnover number $\left(4 \times 10^{5} \mathrm{Pd}^{-1}\right)$ and the amount of catalyst present in the published study. ${ }^{8}$ We also note that this calculation does not take into account the fact that in ref. 8 the concentration of $\mathrm{K}_{2} \mathrm{CO}_{3}$ used was seven times higher $(0.7 \mathrm{M})$ than in this study. However, our overall conclusion remains that by far the most potent agent for the induction of Pd leaching is in fact $\mathrm{K}_{2} \mathrm{CO}_{3}$, and that halogens, as suggested in ref. 8 do not have to be invoked to explain the solubilization of $\mathrm{Pd}$.

Figure 8 shows the reduction of $\mathrm{LaFe}_{0.9} \mathrm{Pd}_{0.1} \mathrm{O}_{3}$ and $\mathrm{LaFe}_{0.95} \mathrm{Pd}_{0.05} \mathrm{O}_{3}$ from the perspective of Pd K-edge EXAFS. Figure 8(a) compares the Fourier transforms of the $\mathrm{k}^{3}$-weighted EXAFS of the two samples at the outlet of the reactor after heating to $353 \mathrm{~K}$ in ethanol/water $/ \mathrm{H}_{2} \mathrm{CO}_{3}$. Figure 8(b) shows how the reduced Pd phase evolves in the two systems as a function of reaction time and temperature. $\mathrm{N}_{1}$ PdPd , i.e. the number of Pd scatterers in the first shell, which is a signature of nanoparticulate $f c c \mathrm{Pd}$ phase, is used as the indicator. To a first approximation, $\mathrm{N}_{1}{ }^{\mathrm{PdPd}}$ provides an estimate of the relative average size of the Pd particles formed. ${ }^{48,49}$

These data show first, that the $\mathrm{Pd}$ in $\mathrm{LaFe}_{0.9} \mathrm{Pd}_{0.1} \mathrm{O}_{3}$ undergoes reduction to a significantly greater degree than in $\mathrm{LaFe}_{0.95} \mathrm{Pd}_{0.05} \mathrm{O}_{3}$, and that the $\mathrm{Pd}$ particles formed as a result of the reaction with the basic solvent mixture are significantly larger than those eventually produced in $\mathrm{LaFe}_{0.95} \mathrm{Pd}_{0.05} \mathrm{O}_{3}$. We are aware of the fact that coordination number in EXAFS is highly correlated with disorder (Debye-Waller (DW) factor): varying levels of disorder in the $f c c$ Pd phase can lead to similar-size particles displaying very different values for $\mathrm{N}_{1}{ }^{\text {PdPd }}$. In our case, however, the significant contribution of low-z coordination to the XAFS envelope in $\mathrm{LaFe}_{0.95} \mathrm{Pd}_{0.05} \mathrm{O}_{3}$ compared to $\mathrm{LaFe}_{0.9} \mathrm{Pd}_{0.1} \mathrm{O}_{3}$ mitigates in favour of a size differential, and a difference in $\mathrm{Pd}$ dispersion, dominating the EXAFS obtained from the Pd nanoparticle phases formed in these two cases. The 
contribution to the EXAFS from oxygen adsorbed at the surface of larger particles will be considerably smaller, as a result of the low Pd dispersion, compared to that for significantly smaller and more highly dispersed $\mathrm{Pd}$ nanoparticles. Lastly, no reduction of the $\mathrm{Pd}$ is observed in the $\mathrm{Pd} @ \mathrm{LaFeO}_{3}$ case under the conditions used.

We note here that it is not easy to explain these differential rates of reduction (Figure 8) and leaching (Figure 7), solely upon the basis of the Pd loading or surface area. For instance, the estimated rates of $\mathrm{Pd}$ leaching in $\mathrm{LaFe}_{0.9} \mathrm{Pd}_{0.1} \mathrm{O}_{3}$ and $\mathrm{LaFe}_{0.95} \mathrm{Pd}_{0.05} \mathrm{O}_{3}$ are about an order of magnitude different, whereas the differences in Pd loading and in surface area are but a factor of 2 and 3 , respectively.

What can be said is that the $\mathrm{Pd}$ hosted in $\mathrm{LaFe}_{0.9} \mathrm{Pd}_{0.1} \mathrm{O}_{3}$ (Figure 8) is reduced more easily, it forms larger $\mathrm{Pd}^{0}$ nanoparticles at the surface of this material and shows a dramatically enhanced propensity for the leaching of that $\mathrm{Pd}$ than $\mathrm{LaFe}_{0.95} \mathrm{Pd}_{0.05} \mathrm{O}_{3}$. These observations may be correlated with an enhanced symmetry of the Pd present in the octahedral sites of $\mathrm{LaFe}_{0.9} \mathrm{Pd}_{0.1} \mathrm{O}_{3}$ derived from XRD. There also exists the possibility that once formed at the surface of the perovskite, any subsequent leaching of the Pd from these particles might be subject to a particle size dependence, with larger particles being eroded more rapidly than smaller ones. However, it is not possible, from within the gamut of possible factors that may be contributing to these differentials in reducibility and leaching, to specify, with any exactitude, a predominant causality.

The stability of the $\mathrm{Pd} @ \mathrm{LaFeO}_{3}$ sample toward the reduction and leaching of the $\mathrm{Pd}$ induced by the addition of the base may, at first sight appear surprising. As EXAFS suggests that this sample substantially comprises very small PdO like species, one might expect these surface species to be as or more reducible than the Pd hosted within the perovskite. ${ }^{34 c}$ However, we have previously shown for $\mathrm{Pd}$ supported upon $\mathrm{Al}_{2} \mathrm{O}_{3}{ }^{22}$ that the reducibility of supported $\mathrm{PdO}$ by the 
solvent alone is a very significant function of the size of the PdO phase. Whilst PdO of $>3-4 \mathrm{~nm}$ diameter is facilely reduced in aqueous ethanol, below ca. $3 \mathrm{~nm}$, this phase becomes much more resistant to reduction to the point where low loaded $(<1 \mathrm{wt} \% \mathrm{Pd})$ are not reduced at all.

Figure 9 shows ex situ $\mathrm{Pd} \mathrm{L}_{3}$-edge XANES from these materials, the $\mathrm{L}_{3}$-edge being more sensitive to the chemical perturbations of the $\mathrm{Pd}$ as a result of a greater sensitivity to valence electronic states and a much reduced energy broadening compared to the deeper K-edge. As might be expected from the Pd K-edge measurements given above (Figure 5 and Figure 6), the more ordered $\mathrm{LaFe}_{0.9} \mathrm{Pd}_{0.1} \mathrm{O}_{3}$ shows, in its dry state, a white line dominated by a single sharp feature $(3.177 \mathrm{keV})$. After reaction with the ethanol/water $/ \mathrm{K}_{2} \mathrm{CO}_{3}$ mixture, this white line structure replaced by a much broader feature with its edge position shifted to lower binding energy (ca. $3.1745 \mathrm{keV}$ ). The latter is consistent with the reduction of a considerable proportion of the $\mathrm{Pd}$ to $\mathrm{Pd}^{0}$ in agreement with the results obtained from the Pd K-edge spectroscopy.

In contrast, $\mathrm{LaFe}_{0.95} \mathrm{Pd}_{0.05} \mathrm{O}_{3}$, in its dry state, displays an $\mathrm{L}_{3}$-edge white line that is split into two components (Figure 9(b)). After reaction with the ethanol/water/ $\mathrm{K}_{2} \mathrm{CO}_{3}$ mixture, the intensity of the high binding energy shoulder relative to the main white line peak is considerably reduced. This suggests the existence of two types of $\mathrm{Pd}$ in this sample, one of which is preferentially removed by exposure to the basic solvent flow. Given the much smaller particles size $(8.1 \mathrm{~nm}$ versus $28 \mathrm{~nm})$ of this perovskite we suggest that these two states arise from $\mathrm{Pd}$ contained within the perovskite-type matrix (as is the vast majority of $\mathrm{Pd}$ in dry $\mathrm{LaFe}_{0.9} \mathrm{Pd}_{0.1} \mathrm{O}_{3}$ ) and $\mathrm{Pd}$ existing in the surface region of the small particles of $\mathrm{LaFe}_{0.95} \mathrm{Pd}_{0.05} \mathrm{O}_{3}$. At present, we cannot relate any of the two peaks with a specific Pd environment also because in these ex-situ measurements the spatial information was lost once the catalyst bed was removed from the in-situ sample holder. 
In the data of $\mathrm{LaFe}_{0.95} \mathrm{Pd}_{0.05} \mathrm{O}_{3}$ (Figure 9(b)) no evidence of a shift of the edge to lower binding energies is observed, contrary to $\mathrm{LaFe}_{0.9} \mathrm{Pd}_{0.1} \mathrm{O}_{3}$ (inset of Figure 9(a)). However, the disappearance of the Pd state corresponding to the high energy white line component, initially seen in the dry catalyst, is still observed. Together with the increase of $\mathrm{N}_{1}{ }^{\text {PdPd }}$ to approximately 7 at 353 $\mathrm{K}$ (Figure $8(\mathrm{~b})$ ) which occurs at later times compared to $\mathrm{LaFe}_{0.9} \mathrm{Pd}_{0.1} \mathrm{O}_{3}$ constitutes further corroborating evidence that the $\mathrm{Pd}^{0}$ entities produced in the $\mathrm{LaFe}_{0.95} \mathrm{Pd}_{0.05} \mathrm{O}_{3}$ are significantly smaller than those produced in $\mathrm{LaFe}_{0.9} \mathrm{Pd}_{0.1} \mathrm{O}_{3}$.

\subsection{Further characterization of materials after exposure to ethanol $/$ water $/ \mathrm{K}_{2} \mathrm{CO}_{3}$}

Figure 10 shows ex-situ Fe K-edge XANES spectra recorded for $\mathrm{LaFe}_{0.9} \mathrm{Pd}_{0.1} \mathrm{O}_{3}$ and $\mathrm{LaFe}_{0.95} \mathrm{Pd}_{0.05} \mathrm{O}_{3}$ in both their dry and reacted (after being heated to $353 \mathrm{~K}$ in flowing ethanol/water $/ \mathrm{K}_{2} \mathrm{CO}_{3}$ ) states. The very different degree to which each of these Pd substituted $\mathrm{LaFeO}_{3}$ based catalysts reacts with the basified solvent mixture is evident. By comparison to $\mathrm{Fe}^{0}$ (Fe foil), $\mathrm{Fe}^{\mathrm{II}}$, (Fe $\mathrm{Fe}^{\mathrm{II}}$ Sulfate) and $\mathrm{Fe}^{\mathrm{III}}$ (Fe ${ }^{\mathrm{III}}$ oxide) references the changes in the spectra shown in Figure 10 indicate that in both cases $\mathrm{Fe}^{\mathrm{III}}$ is being reduced to $\mathrm{Fe}^{\mathrm{II}}$ due to the exposure to flowing ethanol/water $/ \mathrm{K}_{2} \mathrm{CO}_{3}$ at $353 \mathrm{~K}$. This change is much more extensive in the more ordered, more crystalline sample $\left(\mathrm{LaFe}_{0.9} \mathrm{Pd}_{0.1} \mathrm{O}_{3}\right)$ than in its more distorted, less crystalline $\left(\mathrm{LaFe}_{0.95} \mathrm{Pd}_{0.05} \mathrm{O}_{3}\right)$ counterpart.

Scanning transmission electron microscopy (STEM) measurements (Figures S3-S6) establish further details of the nature of the degradation of the perovskite-type structure of $\mathrm{LaFe}_{0.9} \mathrm{Pd}_{0.1} \mathrm{O}_{3}$ induced by $\mathrm{K}_{2} \mathrm{CO}_{3}$. These measurements reveal the extent of the structural heterogeneity that a significant $(0.1 \mathrm{M})$ amount of $\mathrm{K}_{2} \mathrm{CO}_{3}$ induces in an initially highly uniform and crystalline material at $353 \mathrm{~K}$. After reaction with the basified solvent the residual perovskite 
structure is surrounded by an amorphous crust with an average thickness of about $5 \mathrm{~nm}$ (Figure S2). X-ray fluorescence mapping indicates this crust to be rich in Fe and, with more variable concentration, $\mathrm{Pd}$ (Figure S3). Therefore, the resulting material might be indicatively described as $\mathrm{Pd}_{\mathrm{x}} / \mathrm{Fe}_{\mathrm{y}} \mathrm{O}_{\mathrm{z}} @ \mathrm{LaFe}_{0.9-\mathrm{y}} \mathrm{Pd}_{0.1-\mathrm{x}} \mathrm{O}_{3-\mathrm{z}}$. We conclude that under the reaction conditions applied, the role of the perovskite is to provide a reservoir of both $\mathrm{Fe}$ and $\mathrm{Pd}$ that are progressively segregated at the surface of the perovskite particles. There, a new amorphous layer is formed from them and, in the case of the Pd, partial solubilisation to the solvent flow occurs. STEM also provides evidence for the formation of extensive carbonaceous deposits during reaction, indicating that cracking of the organic component of the solvent mixture has also been induced by the presence of the $\mathrm{K}_{2} \mathrm{CO}_{3}$.

Figures 11 (a-c) show the HXRD data obtained for $\mathrm{LaFe}_{0.9} \mathrm{Pd}_{0.1} \mathrm{O}_{3}$ after the experiment with the basified solvent, whilst Figure 11(d-e) shows the PDF obtained from this data. $\mathrm{HXRD} / \mathrm{PDF}$ indicate that the exposure to the ethanol/water $/ \mathrm{H}_{2} \mathrm{CO}_{3}$ solvent at $353 \mathrm{~K}$ results in the loss of La to a secondary crystalline phase and the reduction and consequent partial leaching of Pd into the reaction mixture.

The crystal structure and crystallite size of the perovskite phase in the reacted sample is very similar to that of the unreacted $\mathrm{LaFe}_{0.9} \mathrm{Pd}_{0.1} \mathrm{O}_{3}$ although it constitutes a smaller fraction of the crystalline material. A multiphase Rietveld refinement of the diffraction pattern evidences that the crystalline part of the sample volume probed consists of $88.5 \%( \pm 2)$ perovskite and $11.5 \%( \pm 2) \mathrm{La}$ hydroxycarbonate, $\mathrm{La}_{2}\left(\mathrm{CO}_{3}\right)_{2}(\mathrm{OH})_{2}$. None of the secondary peaks could be assigned to various iron oxides, a sign that Fe has migrated to the particle's amorphous crust (as suggested by STEM) or to a region closer to the reactor outlet. The loss of La to a secondary phase also aids in rationalization of the accumulation of both Fe and $\mathrm{Pd}$ in the (amorphous) surface layer of the perovskite particles observed by STEM and XAS, respectively. The presence most likely of La- 
carbonates was confirmed by the comparison of ATR-IR spectra of the materials prior to and after the experiment (Figure S7). Interestingly, the irreducibility of $\mathrm{Pd} @ \mathrm{LaFeO}_{3}$ was reflected in the absence of this phase in its spectrum after the experiment with the base.

At least part of the reduced $\mathrm{Pd}$ is leached from the catalyst, as suggested by the small improvement of the Rietveld refinement that is achieved upon including a $f c c$ Pd phase with broad peaks in the structural model (Figure 11(b)). In addition, we note that a smaller tilt angle $\varphi_{\mathrm{x}}$, with respect to dry $\mathrm{LaFe}_{0.9} \mathrm{Pd}_{0.1} \mathrm{O}_{3}$, and in line with the unsubstituted $\mathrm{LaFeO}_{3}$ and $\mathrm{Pd} @ \mathrm{LaFeO}_{3}(\mathrm{Tables}$ S1-S5), is consistent with a smaller average size of the cations in the perovskite B site, and thus a much lower occupancy by $\mathrm{Pd}^{3+}$. Segregated $\mathrm{Pd}^{0}$ gives rise to $\mathrm{Pd}-\mathrm{Pd}$ first neighbour correlations $(r=2.75 \AA)$ that appear in the PDF of the reacted sample, that contribute to the increased high- $r$ component of the La-O doublet as compared to the dry $\mathrm{LaFe}_{0.9} \mathrm{Pd}_{0.1} \mathrm{O}_{3}$ sample (marked with an asterisk in Figure 11(d)).

The degradation of the perovskite core resulting in a reduced crystallite size could not be inferred from an increased Pseudo-Voigt peak width within the relatively low resolution of the HXRD data (Tables S2, S5). We have therefore looked at the intensity fall-off of the PDF of the two samples (see details in the supporting information). Similar to what was noted previously for the perovskite unit cell parameters, the amplitude of the PDF of the $\mathrm{LaFe}_{0.9} \mathrm{Pd}_{0.1} \mathrm{O}_{3}$ before and after reaction with basified solvent shows no change. This suggests that the leaching of $\mathrm{Pd}, \mathrm{Fe}$, and $\mathrm{La}$ induced by our experiment does not disrupt the bulk perovskite-type structure, and leads to the further conclusion that leaching, and the formation of new phases that arise from contact with the basified solvent at $353 \mathrm{~K}$ affects mainly the outermost layers of the material.

\section{Conclusions}


Using space and time-resolved QEXAFS applied within a plug flow reactor we established that $\mathrm{Pd}$ within and upon $\mathrm{LaFeO}_{3}$ perovskite-based catalysts is not subject to reduction or significant leaching during heating under a flow of aqueous ethanol. However, when $\mathrm{K}_{2} \mathrm{CO}_{3}$ is added to this solvent significant reduction and then leaching of Pd from the perovskite occurs in the absence of any halogenated components.

In $\mathrm{LaFe}_{0.9} \mathrm{Pd}_{0.1} \mathrm{O}_{3}$, the catalyst with the highest crystallinity and the smallest orthorhombic distortion, ca. $60 \%$ of the $\mathrm{Pd}$ present at the inlet of the catalyst bed can be stripped from the support in the presence of $\mathrm{K}_{2} \mathrm{CO}_{3}$. By contrast, we observed a greater resistance to reduction and leaching of the Pd in the two catalysts based on more nano-sized and orthorhombically more distorted perovskites.

If, however, $\mathrm{Pd}$ has been deposited upon rather than within the $\mathrm{LaFeO}_{3}$ support, the addition of the $\mathrm{K}_{2} \mathrm{CO}_{3}$ to the solvent flow has no effect on either the Pd present or the structure of the perovskite: the Pd adsorbed at the surface of the perovskite appears to provide an irreducible barrier to structural degradation of the support by the combined actions of the solvent and the base.

Concomitant with the reduction and leaching of Pd from within the highly structured perovskite, the presence of the base provokes structural changes of the outer regions of the perovskite particles. Reduction and segregation of a fraction of the $\mathrm{Fe}^{\mathrm{III}}$ present to $\mathrm{Fe}^{\mathrm{II}}$ occurs alongside that of $\mathrm{Pd}$ in the presence of the base, and results in the deposition of amorphous $\mathrm{FeO}_{\mathrm{x}}$ phases apparent as an amorphous crust around the perovskite particles in STEM.

Whilst the starting materials contain one single crystalline phase, reaction with the basified solvent at $353 \mathrm{~K}$ results in the facile transformation of $\mathrm{LaFe}_{0.9} \mathrm{Pd}_{0.1} \mathrm{O}_{3}$ into a segregated system that has lost much of Pd to the solvent flow. After reaction the sample contains significant 
amounts of secondary phases of $\mathrm{Pd}^{0}, \mathrm{La}$, and Fe deposited around the perovskite particles. The bulk perovskite phase, however, appears to remain structurally intact after the leaching of $\mathrm{Pd}$.

These results suggest that predictions made about the behaviour of Perovskite-type materials based upon the notion of the retention of an ideal starting structure and composition may not be valid in such a working system, especially when elevated $\mathrm{pH}$ must be experienced as a result of the applied process conditions. Our approach also demonstrates how commonly applied batch approach to studying such systems and catalysis can very effectively mask the real levels of Pd leaching occurring in such systems.

\section{Acknowledgements}

MAN would like to thank the department of Physics at the University of Warwick, UK, for a visiting scientist position under the auspices of which this work was carried out. He would like to thank Shell Global solutions for funding of his current position. We thank the ESRF, SwissNorwegian beamlines, and XMaS for access to synchrotron facilities. STEM measurements were conducted at the Scientific Center for Optical and Electron Microscopy (ScopeM, ETH Zürich). $\mathrm{CJM} / \mathrm{KKH}$ thank EPSRC and Astra Zeneca for the award of a studentship to CJM. DF would like to thank the Competence Centre for Materials Science and Technology (CCMX) for financial support.

\section{Supporting information material}


Rietveld refinement of HXRD data; phase composition of the samples; scaling factors in PDF; STEM images of $\mathrm{LaFe}_{0.9} \mathrm{Pd}_{0.1} \mathrm{O}_{3}$ after exposure to ethanol/water/ $\mathrm{K}_{2} \mathrm{CO}_{3}$; ATR-IR spectra of the samples and of $\mathrm{K}_{2} \mathrm{CO}_{3}$.

\section{References}

[1] Goodenough, J. B. Electronic and Ionic Transport Properties and Other Physical Aspects of Perovskites. Rep. Prog. Phys. 2004, 67, 1915-1993.

[2] For instance: (a) Royer, S.; Duprez, D.; Can, F.; Courtois, X.; Batiot-Dupeyrat, C.; Laassiri, S.; Alamdari, H. Perovskites as Substitutes of Noble Metals for Heterogeneous Catalysis: Dream or Reality. Chem. Rev. 2014, 114, 10292-10368.; (b) Royer, S.; Duprez, D. Catalytic Oxidation of Carbon Monoxide over Transition Metal Oxides. ChemCatChem 2011, 3, 24-65; (c) Essoumhi, A.; Kazzouli, S. E.; Bousmina, M. Review on Palladium-Containing Perovskites: Synthesis, Physico-Chemical Properties and Applications in Catalysis. J. nanosci. nanotech. 2014, 14, 2012-2023.; (d) Zhu, Y.; Zhou, W.; Chen, Y.; Yu, J.; Xu, X.; Su, C.; Tadé, M. O.; Shao, Z. Boosting Oxygen Reduction Reaction Activity of Palladium by Stabilizing Its Unusual Oxidation States in Perovskite. Chem. Mater. 2015, 27, 3048-3054..

[3] For instance: (a) Labhasetwar, N.; Saravanan, G.; Kumar Megarajan, S.; Manwar, N.; Khobragade, R.; Doggali, P.; Grasset, F. Perovskite-Type Catalytic Materials for Environmental Applications. Science and Technology of Advanced Materials 2015, 16, 036002; (b) Gupta, S.; Kellogg, W.; Xu, H.; Liu, X.; Cho, J.; Wu, G. Bifunctional Perovskite Oxide Catalysts for Oxygen Reduction and Evolution in Alkaline Media. Chem. Asian J. 2016, 11, 10-21; (c) Cheng, F.; Chen, J. Metal-Air Batteries: From Oxygen Reduction Electrochemistry to Cathode Catalysts. Chem. Soc. Rev. 2012, 41, 2172.

[4] For instance; (a) Green, M. A.; Ho-Baillie, A.; Snaith, H. J. The Emergence of Perovskite Solar Cells. Nature Photon 2014, 8, 506-514; (b) Kazim, S.; Nazeeruddin, M. K.; Grätzel, M.; Ahmad, S. Perovskite as Light Harvester: A Game Changer in Photovoltaics. Angew. Chem. Int. Ed. 2014, 53, 2812-2824; (c) Niu, G.; Guo, X.; Wang, L. Review of Recent Progress in Chemical Stability of Perovskite Solar Cells. J. Mater. Chem. A 2015, 3, 8970-8980; (d) Wang, W.; Tadé, M. O.; Shao, Z. Research Progress of Perovskite Materials in Photocatalysis- and 
Photovoltaics-Related Energy Conversion and Environmental Treatment. Chem. Soc. Rev. 2015, 44, 5371-5408.

[5] Fabbri, E.; Nachtegaal, M.; Binninger, T.; Cheng, X.; Kim, B.-J.; Durst, J.; Bozza, F.; Graule, T.; Schäublin, R.; Wiles, L.; Pertoso, M.; Danilovic, N.; Ayers, K. E., Schmidt, T. J., Dynamic Surface Self-Reconstruction Is the Key of Highly Active Perovskite Nano-Electrocatalysts for Water Splitting. Nature Mater 2017, 16, 925-931.

[6] Grimaud, A.; May, K. J.; Carlton, C. E.; Lee, Y.-L.; Risch, M.; Hong, W. T.; Zhou, J.; ShaoHorn, Y. Double Perovskites as a Family of Highly Active Catalysts for Oxygen Evolution in Alkaline Solution. Nat Commun 2013, 4, 2439.

[7] (a) Nishihata, Y.; Mizuki, J.; Akao, T.; Tanaka, H.; Uenishi, M.; Kimura, M.; Okamoto, T.; Hamada, N. Self-Regeneration of a Pd-Perovskite Catalyst for Automotive Emissions Control. Nature 2002, 418, 164-167; (b) Uenishi, M.; Taniguchi, M.; Tanaka, H.; Kimura, M.; Nishihata, Y.; Mizuki, J.; Kobayashi, T. Redox Behavior of Palladium at Start-up in the Perovskite-Type LaFePdOx Automotive Catalysts Showing a Self-Regenerative Function. Applied Catalysis B: Environmental 2005, 57, 267-273; (c) Tanaka, H.; Uenishi, M.; Taniguchi, M.; Tan, I.; Narita, K.; Kimura, M.; Kaneko, K.; Nishihata, Y.; Mizuki, J. The Intelligent Catalyst Having the Self-Regenerative Function of $\mathrm{Pd}, \mathrm{Rh}$ and $\mathrm{Pt}$ for Automotive Emissions Control. Catalysis Today 2006, 117, 321-328; (d) Tanaka, H.; Taniguchi, M.; Uenishi, M.; Kajita, N.; Tan, I.; Nishihata, Y.; Mizuki, J.; Narita, K.; Kimura, M.; Kaneko, K. Self-Regenerating Rh- and Pt-Based Perovskite Catalysts for Automotive-Emissions Control. Angew. Chem. Int. Ed. 2006, 45, 5998-6002.; (e) Hamada, I.; Uozumi, A.; Morikawa, Y.; Yanase, A.; Katayama-Yoshida, H. A Density Functional Theory Study of Self-Regenerating Catalysts $\mathrm{LaFe}_{1-x} \mathrm{M}_{x} \mathrm{O}_{3-y}(\mathrm{M}=\mathrm{Pd}, \mathrm{Rh}, \mathrm{Pt}) . J$. Am. Chem. Soc. 2011, 133, 18506-18509.

[8] Andrews, S.; Stepan, A.; Tanaka, H.; Ley, S.; Smith, M. Heterogeneous or Homogeneous? A Case Study Involving Palladium-Containing Perovskites in the Suzuki Reaction. Advanced Synthesis \& Catalysis 2005, 347, 647-654.

[9] Lohmann, S.; Andrews, S. P.; Burke, B.; Smith, M.; Attfield, J. P.; Tanaka, H.; Kaneko, K.; Ley, S. V. Copper- and Palladium-Containing Perovskites: Catalysts for the Ullmann and Sonogashira Reactions. Synlett 2005, 1291-1295. 
[10] Misch, L. M.; Birkel, A.; Figg, C. A.; Fors, B. P.; Hawker, C. J.; Stucky, G. D.; Seshadri, R. Rapid Microwave-Assisted Sol-Gel Preparation of Pd-Substituted $\mathrm{LnFeO}_{3}$ (Ln = Y, La): Phase Formation and Catalytic Activity. Dalton Trans. 2014, 43, 2079-2087.

[11] Ji, Y.; Jain, S.; Davis, R. J. Investigation of Pd Leaching from Supported Pd Catalysts during the Heck Reaction. Journal of Physical Chemistry B, 2005, 109, 17232-17238.

[12] Hübner, S.; de Vries, J. G.; Farina, V. Why Does Industry Not Use Immobilized Transition Metal Complexes as Catalysts? Adv. Synth. Catal. 2016, 358, 3-25.

[13] Blaser, H.-U.; Indolese, A.; Schnyder, A.; Steiner, H.; Studer, M. Supported Palladium Catalysts for Fine Chemicals Synthesis. Journal of Molecular Catalysis A: Chemical 2001, 173, $3-18$.

[14] Weck, M.; Jones, C. W. Mizoroki-Heck Coupling Using Immobilized Molecular Precatalysts: Leaching Active Species from Pd Pincers, Entrapped Pd Salts, and Pd NHC Complexes. Inorg. Chem. 2007, 46, 1865-1875.

[15] Pachón, L. D.; Rothenberg, G. Transition-Metal Nanoparticles: Synthesis, Stability and the Leaching Issue. Appl. Organometal. Chem. 2008, 22, 288-299.

[16] Cantillo, D.; Kappe, C. O. Immobilized Transition Metals as Catalysts for Cross-Couplings in Continuous Flow-A Critical Assessment of the Reaction Mechanism and Metal Leaching. ChemCatChem 2014, 6, 3286-3305.

[17] Reimann, S.; Stötzel, J.; Frahm, R.; Kleist, W.; Grunwaldt, J.-D.; Baiker, A. Identification of the Active Species Generated from Supported Pd Catalysts in Heck Reactions: An in Situ Quick Scanning EXAFS Investigation. J. Am. Chem. Soc. 2011, 133, 3921-3930.

[18] Gaikwad, A. V.; Holuigue, A.; Thathagar, M. B.; ten Elshof, J. E.; Rothenberg, G. Ion- and Atom-Leaching Mechanisms from Palladium Nanoparticles in Cross-Coupling Reactions. Chem. Eur. J. 2007, 13, 6908-6913.

[19] Deraedt, C.; Astruc, D. "Homeopathic” Palladium Nanoparticle Catalysis of Cross CarbonCarbon Coupling Reactions. Acc. Chem. Res. 2014, 47, 494-503.

[20] Hii, K. K.; Hellgardt, K. Catalysis in Flow: Why Leaching Matters. In Organometallic Flow Chemistry; Noël, T., Ed.; Springer International Publishing: Cham, 2015; Vol. 57, pp 249-262.. [21] Brazier, J. B.; Nguyen, B. N.; Adrio, L. A.; Barreiro, E. M.; Leong, W. P.; Newton, M. A.; Figueroa, S. J. A.; Hellgardt, K.; Hii, K. K. M. Catalysis in Flow: Operando Study of Pd Catalyst Speciation and Leaching. Catalysis Today 2014, 229, 95-103. 
[22] Newton, M. A.; Brazier, J. B.; Barreiro, E. M.; Parry, S.; Emmerich, H.; Adrio, L. A.; Mulligan, C. J.; Hellgardt, K.; Hii, K. K. (Mimi). Operando XAFS of Supported Pd Nanoparticles in Flowing Ethanol/Water Mixtures: Implications for Catalysis. Green Chem. 2016, $18,406-411$.

[23] Newton, M. A.; Brazier, J. B.; Barreiro, E. M.; Emerich, H.; Adrio, L. A.; Mulligan, C. J.; Hellgardt, K.; Hii, K. K. (Mimi). Restructuring of Supported Pd by Green Solvents: An Operando Quick EXAFS (QEXAFS) Study and Implications for the Derivation of StructureFunction Relationships in Pd Catalysis. Catal. Sci. Technol. 2016, 6, 8525-8531.

[24] Brazier, J. B.; Newton, M. A.; Barreiro, E. M.; Parry, S.; Adrio, L. A.; Mulligan, C. J.; Hellgardt, K.; Hii, K. K. (Mimi); Thompson, P. B. J.; Nichols, R.; Nguyen B. N., Effects of Cl on the Reduction of Supported PdO in Ethanol/Water Solvent Mixtures. Catalysis, Structure \& Reactivity 2017, 3, 54-62.

[25] Newton, Mark. A.; Nicholls, R.; Brazier, J. B.; Nguyen, B. N.; Mulligan, C. J.; Hellgardt, K.; Barreiro, E. M.; Emerich, H.; Hii, K. K. (Mimi); Snigireva, I.; Thompson P. B. J., Effect of Retained Chlorine in ENCAT ${ }^{\mathrm{TM}} 30$ Catalysts on the Development of Encapsulated Pd: Insights from in Situ Pd K, L 3 and Cl K-Edge XAS. Catalysis, Structure \& Reactivity 2017, 3, 149-156. [26] Amini-Rentsch, L.; Vanoli, E.; Richard-Bildstein, R.; Marti, R.; Vilé, G.o, Ind. Eng. Chem. Res., 2019, 58, 10164-10171.

[27] Jas, G.; Kirschning, A. Continuous Flow Techniques in Organic Synthesis. Chem. Eur. J. 2003, 9, 5708-5723.

[28] Glasnov, T. N.; Findenig, S.; Kappe, C. O. Heterogeneous Versus Homogeneous Palladium Catalysts for Ligandless Mizoroki-Heck Reactions: A Comparison of Batch/Microwave and Continuous-Flow Processing. Chem. Eur. J. 2009, 15, 1001-1010.

[29] Irfan, M.; Glasnov, T. N.; Kappe, C. O. Heterogeneous Catalytic Hydrogenation Reactions in Continuous-Flow Reactors. ChemSusChem 2011, 4, 300-316.

[30] Newman, S. G.; Jensen, K. F. The Role of Flow in Green Chemistry and Engineering. Green Chem. 2013, 15, 1456.

[31] Pastre, J. C.; Browne, D. L.; Ley, S. V. Flow Chemistry Syntheses of Natural Products. Chem. Soc. Rev. 2013, 42, 8849 .

[32] Zhao, D.; Ding, K. Recent Advances in Asymmetric Catalysis in Flow. ACS Catal. 2013, 3, 928-944. 
[33] Porta, R.; Benaglia, M.; Puglisi, A. Flow Chemistry: Recent Developments in the Synthesis of Pharmaceutical Products. Org. Process Res. Dev. 2016, 20, 2-25.

[34] a) Rossetti, I.; Compagnoni, M. Chemical Reaction Engineering, Process Design and Scaleup Issues at the Frontier of Synthesis: Flow Chemistry. Chemical Engineering Journal 2016, 296, 56-70. b) Eyssler, A., Kleymenov, E., Kupferschmid, A., Nachtegaal, M., Kumar, M.S., Hug, P., Weidenkaff, A., Ferri, D. Improvement of Catalytic Activity of $\mathrm{LaFe}_{0.95} \mathrm{Pd}_{0.05} \mathrm{O}_{3}$ for Methane Oxidation under Transient Conditions. J. Phys. Chem. C 2011, 115, 1231-1239. c) Eyssler, A., Mandaliev, P., Winkler, A., Hug, P., Safonova, O., Figi, R., Weidenkaff, A., Ferri, D. The Effect of the State of Pd on Methane Combustion in Pd-Doped $\mathrm{LaFeO}_{3}$. J. Phys. Chem. C 2010, 114, 4584-4594.

[35] For instance, Chan, E. M.; Marcus, M. A.; Fakra, S.; El Naggar, M.; Mathies, R. A.; Alivisatos, A. P. Millisecond Kinetics of Nanocrystal Cation Exchange Using Microfluidic XRay Absorption Spectroscopy. J. Phys. Chem. A 2007, 111, 12210-12215.

[36] $\mathrm{LaFeO}_{3}$ and $\mathrm{LaFe}_{0.9} \mathrm{Pd}_{0.1}$ (Lot number A4KOH) was supplied to us by Daihatsu (Dr $\mathrm{H}$. Tanaka)

[37] Eyssler, A.; Mandaliev, P.; Winkler, A.; Hug, P.; Safonova, O.; Figi, R.; Weidenkaff, A.; Ferri, D. The Effect of the State of Pd on Methane Combustion in Pd-Doped LaFeO 3. J. Phys. Chem. C 2010, 114, 4584-4594.

[38] Chiarello, G. L.; Nachtegaal, M.; Marchionni, V.; Quaroni, L.; Ferri, D. Adding Diffuse Reflectance Infrared Fourier Transform Spectroscopy Capability to Extended X-RayAbsorption Fine Structure in a New Cell to Study Solid Catalysts in Combination with a Modulation Approach. Review of Scientific Instruments 2014, 85, 074102..

[39] Marchionni, V.; Kambolis, A.; Nachtegaal, M.; Kröcher, O.; Ferri, D. High Energy X-Ray Diffraction and IR Spectroscopy of Pt/A12O3 during CO Oxidation in a Novel Catalytic Reactor Cell. Catalysis, Structure \& Reactivity 2017, 3, 71-78.

[40] Thompson, P. B. J.; Nguyen, B. N.; Nicholls, R.; Bourne, R. A.; Brazier, J. B.; Lovelock, K. R. J.; Brown, S. D.; Wermeille, D.; Bikondoa, O.; Lucas, C. A.; Hase T. P. A.; Newton M. A., X-Ray Spectroscopy for Chemistry in the 2-4 KeV Energy Regime at the XMaS Beamline: Ionic Liquids, $\mathrm{Rh}$ and $\mathrm{Pd}$ Catalysts in Gas and Liquid Environments, and $\mathrm{Cl}$ Contamination in $\gamma-\mathrm{Al}_{2} \mathrm{O}_{3} . J$ Synchrotron Rad 2015, 22, 1426-1439.. 
[41] Binsted, N., PAXAS: Programme for the analysis of X-ray adsorption spectra, University of Southampton, 1988.

[42] Figueroa, S. J. A.; Prestipino, C. PrestoPronto: A Code Devoted to Handling Large Data Sets. J. Phys.: Conf. Ser. 2016, 712, 012012.

[43] Binsted, N., EXCURV98 CCLRC Daresbury Laboratory computer program, 1998

[44] Ashiotis, G.; Deschildre, A.; Nawaz, Z.; Wright, J. P.; Karkoulis, D.; Picca, F. E.; Kieffer, J. The Fast Azimuthal Integration Python Library: PyFAI. J Appl Crystallogr 2015, 48, 510-519. [45] Knudsen, E. B.; Sørensen, H. O.; Wright, J. P.; Goret, G.; Kieffer, J. FabIO: Easy Access to Two-Dimensional X-Ray Detector Images in Python. J Appl Crystallogr 2013, 46, 537-539.

[46] Keen, D. A. A Comparison of Various Commonly Used Correlation Functions for Describing Total Scattering. J Appl Crystallogr 2001, 34, 172-177.

[47] Juhás, P.; Davis, T.; Farrow, C. L.; Billinge, S. J. L. PDFgetX3: A Rapid and Highly Automatable Program for Processing Powder Diffraction Data into Total Scattering Pair Distribution Functions. J Appl Crystallogr 2013, 46, 560-566.

[48] Farrow, C. L.; Juhas, P.; Liu, J. W.; Bryndin, D.; Božin, E. S.; Bloch, J.; Proffen, T.; Billinge, S. J. L. PDFfit2 and PDFgui: Computer Programs for Studying Nanostructure in Crystals. J. Phys.: Condens. Matter 2007, 19, 335219.

[49] Benfield, R. E. Mean Coordination Numbers and the Non-Metal-Metal Transition in Clusters. J. Chem. Soc., Faraday Trans. 1992, 88, 1107-1110.

[50] Jentys, A. Estimation of Mean Size and Shape of Small Metal Particles by EXAFS. Phys. Chem. Chem. Phys. 1999, 1, 4059-4063.

[51] Checchia, S.; Scavini, M.; Allieta, M.; Brunelli, M.; Ferrero, C.; Coduri, M. Size and Spatial Correlation of Defective Domains in Yttrium-Doped CeO ${ }_{2}$. Powder Diffr. 2015, 30, S119S126.

[52] a) Balzar, D. Profile Fitting of X-Ray Diffraction Lines and Fourier Analysis of Broadening. J Appl Crystallogr 1992, 25, 559-570; b) Balzar, D.; Ledbetter, H. Voigt-Function Modeling in Fourier Analysis of Size- and Strain-Broadened X-Ray Diffraction Peaks. J Appl Crystallogr 1993, 26, 97-103.; c) Balzar, D.; Audebrand, N.; Daymond, M. R.; Fitch, A.; Hewat, A.; Langford, J. I.; Le Bail, A.; Louër, D.; Masson, O.; McCowan, C. N.; Popa, N. C.; Stephens P. W.; Toby, B. H., Size-Strain Line-Broadening Analysis of the Ceria Round-Robin Sample. J Appl Crystallogr 2004, 37, 911-924. 
[53] Vaughan, G.; Baker, R.; Barret, R.; Bonnefoy, J; Buslaps, T; Checchia, S.; Duran, D.; Fihman, F.; Kieffer, J.; Kimber, S.; Martel, K.; Morawe, C.; Mottin, D.; Papillon, E.; Petitdemange, S.; Vieux, J.-P.; Di Michiel, M.; ID15A at the ESRF, a beamline for high speed operando X-ray diffraction, diffraction tomography, and total scattering. J. Synchrotron Rad., 2019, under review.

[54] Kennedy, B. J.; Howard, C. J.; Chakoumakos, B. C. Phase Transitions in Perovskite at Elevated Temperatures - a Powder Neutron Diffraction Study. J. Phys.: Condens. Matter 1999, $11,1479-1488$. 


\section{Figures captions.}

Figure 1. Schematic representation of the steps involved in the Suzuki reaction catalysed by $\mathrm{LaFe}(\mathrm{Co})_{\mathrm{x}} \mathrm{Pd}_{(1-\mathrm{x})} \mathrm{O}_{3}$ as concluded by Andrews et al. ${ }^{8}$ Initially oxidised $\mathrm{Pd}$ held within the perovskite structure must be reduced and presented to the reaction mixture at the catalyst surface whereupon it is solubilised to yield the catalytically active site. This solubilised Pd is then redeposited on the perovskite post reaction.

Figure 2. HXRD patterns of the samples in their as received state: (a) $\mathrm{LaFeO}_{3}$; (b) $\mathrm{LaFe}_{0.9} \mathrm{Pd}_{0.1} \mathrm{O}_{3}$; (c) $\mathrm{LaFe}_{0.95} \mathrm{Pd}_{0.05} \mathrm{O}_{3}$; (d) $\mathrm{Pd} @ \mathrm{LaFeO}_{3}$. Black symbols refer to the experimental data; the red lines are the fits to the data derived from Rietveld analysis; the green lines are the residuals (black-red). The insets show a close-up view of the low $Q\left(\AA^{-1}\right)$ data range. Details of the structural analysis are given in the supporting information.

Figure 3. PDF of the samples in their as received states along with the PDF due to the $\mathrm{CeO}_{2}$ reference material. (a) Complete G(r) envelopes from 0 to $200 \AA$; (b) Close up of the G(r in the 1.5 to $10 \AA$ range, for the four perovskite samples, along with fits to the data (red) and residuals (green).

Figure 4. General model of the orthorhombic Pbnm structure found for the different perovskite samples measured in this work. The unit cell atoms are: $\mathrm{La}(4 c, \sim 0, \sim 0.5,0.25)$ (grey); Fe/Pd (4a, $0,0,0)$ (atoms with mixed occupancy in gold, emphasized Pd atom in green); $\mathrm{O} 1(4 c, \sim 0, \sim 0,0.25)$ (red); $\mathrm{O} 2(8 d, 0.25-u, 0.25+v, w)$ (red). 
The first-neighbour Pd-O and Pd-Fe distances are indicated by the brackets. The tilt angles $\varphi_{\mathrm{x}}$ and $\varphi_{\mathrm{z}}$ are calculated, respectively, as $\tan ^{-1}(2 u+2 v)$ and $\tan ^{-1}(4 \sqrt{2} w) .{ }^{53}$

Figure 5. Pd K-edge EXAFS obtained from the three catalysts studied in their dry state. (a) $\mathrm{k}^{3}$ weighted EXAFS; (b) Fourier transforms of the $\mathrm{k}^{3}$-weighted EXAFS. The red lines are the fits arising from analysis in EXCURV. ${ }^{40}$

Figure 6. Background subtracted $\mathrm{Pd} \mathrm{K}$-edge XANES spectra of $\mathrm{LaFe}_{0.9} \mathrm{Pd}_{0.1} \mathrm{O}_{3}$ system collected at the reactor inlet and reactor outlet under heating in ethanol/water ((a) and (c)) and under ethanol/water $/ \mathrm{K}_{2} \mathrm{CO}_{3}((\mathrm{~b})$ and $(\mathrm{d}))$. The arrows indicate the direction of the changes with increasing temperature.

Figure 7. Variation in $\mathrm{Pd}$ K-edge jump of: (a) $\mathrm{LaFe}_{0.9} \mathrm{Pd}_{0.1} \mathrm{O}_{3}$; (b) $\mathrm{LaFe}_{0.95} \mathrm{Pd}_{0.05} \mathrm{O}_{3}$; and (c) $\mathrm{Pd}$ (a) $\mathrm{LaFeO}_{3}$ during heating to $353 \mathrm{~K}$ and dwelling in ethanol/water $/ \mathrm{K}_{2} \mathrm{CO}_{3}$. In each case the Pd $\mathrm{K}$-edge jump has been normalised to the value obtained at each axial position in the bed once the sample has been made wet in the ethanol/water $/ \mathrm{K}_{2} \mathrm{CO}_{3}$ at room temperature.

Figure 8. (a) Fourier transforms of the $\mathrm{k}^{3}$-weighted Pd K-edge EXAFS derived from the outlet of beds comprised of $\mathrm{LaFe}_{0.9} \mathrm{Pd}_{0.1} \mathrm{O}_{3}$ and $\mathrm{LaFe}_{0.95} \mathrm{Pd}_{0.05} \mathrm{O}_{3}$, at $353 \mathrm{~K}$. The red lines are fits to the data. (b) Evolution of the coordination number of the Pd-Pd first neighbour $\left(\mathrm{N}_{1}{ }^{\mathrm{PdPd}}\right)$, as a function of time and temperature for $\mathrm{LaFe}_{0.9} \mathrm{Pd}_{0.1} \mathrm{O}_{3}(\bullet)$ and $\mathrm{LaFe}_{0.95} \mathrm{Pd}_{0.05} \mathrm{O}_{3}(\bullet)$. The black line represents temperature. 
Figure 9. $\mathrm{Pd} \mathrm{L}$-edge XANES of (a) $\mathrm{LaFe}_{0.9} \mathrm{Pd}_{0.1} \mathrm{O}_{3}$ and (b) $\mathrm{LaFe}_{0.95} \mathrm{Pd}_{0.05} \mathrm{O}_{3}$ in their dry state (black) and post reaction with ethanol/water $/ \mathrm{K}_{2} \mathrm{CO}_{3}$ (red). The inset shows expanded views of the white line regions of the spectra.

Figure 10. Fluorescence yield Fe K-edge XANES of (a) $\mathrm{LaFe}_{0.9} \mathrm{Pd}_{0.1} \mathrm{O}_{3}$ and (b) $\mathrm{LaFe}_{0.95} \mathrm{Pd}_{0.05} \mathrm{O}_{3}$ from both dry samples (black) and after reaction in flowing EtOH/ $\mathrm{H}_{2} \mathrm{O}+\mathrm{K}_{2} \mathrm{CO}_{3}$ (red).

Figure 11. (a) $\mathrm{HXRD}$ pattern of $\mathrm{LaFe}_{0.9} \mathrm{Pd}_{0.1} \mathrm{O}_{3}$ after reaction in flowing $\mathrm{EtOH} / \mathrm{H}_{2} \mathrm{O}+\mathrm{K}_{2} \mathrm{CO}_{3}$. (b) Comparison of the Rietveld refinements including the Pd phase and without in the region around the $\mathrm{Pd} 111$ reflection. (c) Close-up view of the low- $Q$ range; dotted lines indicate peaks belonging to the $\mathrm{La}_{2}\left(\mathrm{CO}_{3}\right)_{2}(\mathrm{OH})_{2}$ phase and a dashed line points to the Pd 111 reflection. (d) The PDF curves of $\mathrm{LaFe}_{0.9} \mathrm{Pd}_{0.1} \mathrm{O}_{3}$ before reaction (top) and after reaction(bottom) fitted in the range $r \leq 10 \AA$ with the Pbnm orthorhombic model; black symbols are the experimental data, red lines the calculated PDF, green lines the fit residual; an asterisk indicates the position of the Pd-Pd first-neighbour distance. (e) The full-range PDF curves of $\mathrm{LaFe}_{0.9} \mathrm{Pd}_{0.1} \mathrm{O}_{3}$ before reaction (top) and after reaction (bottom). 
Table 1. Structural and statistical parameters derived from fitting of the Pd K-edge EXAFS data shown in Figure 5.

\begin{tabular}{|r|c|c|c|c|c|}
\hline & $\mathrm{r}(\AA)^{\mathrm{a}}$ & $\mathrm{CN}^{\mathrm{b}}$ & $\mathrm{DW}\left(2 \sigma^{2}\right)^{\mathrm{c}}$ & $\mathrm{E}_{\mathrm{F}}^{\mathrm{d}}$ & $\mathrm{R}^{\mathrm{e}}$ \\
\hline $\mathrm{LaFe}{ }_{0.9} \mathrm{Pd}_{0.1} \mathrm{O}_{3}$ & & & & & \\
\hline $\mathrm{Oe}$ & 3.68 & 5.5 & 0.026 & & 38.77 \\
\hline $\mathrm{LaFe}_{0.95} \mathrm{Pd}_{0.05} \mathrm{O}_{3}$ & & & & & \\
\hline $\mathrm{O}$ & 2.00 & 5.3 & 0.007 & 3.393 & 45.1 \\
\hline $\mathrm{Fe}$ & 2.90 & 0.8 & 0.009 & & \\
\hline $\mathrm{Fe}$ & 3.61 & 3.3 & 0.018 & & \\
\hline $\mathrm{Pd} @ \mathrm{LaFeO}_{3}$ & & & & & \\
\hline $\mathrm{O}$ & 2.01 & 5.0 & 0.008 & -4.56 & 53.7 \\
\hline $\mathrm{Pd}$ & 3.03 & 0.9 & 0.01 & & \\
\hline $\mathrm{Pd}$ & 3.41 & 1.2 & 0.01 & & \\
\hline $\mathrm{Fe}$ & 3.62 & 2.7 & 0.026 & & \\
\hline & & & & & \\
\hline
\end{tabular}

${ }^{a}$ Distance of the scattering atom from central atom $( \pm 1.5 \%$ of stated value $) ;{ }^{c}$ Debye-Waller factor; $\sigma$ is the root mean square inter-nuclear separation $(\AA)$.

${ }^{\mathrm{b}}$ Coordination number $( \pm 10 \%$ of stated value).

${ }^{d}$ Edge position relative to the vacuum zero (Fermi energy, eV).

${ }^{\mathrm{e}} \mathrm{R} \%=\left(\int\left[\mathrm{c}^{\mathrm{T}}-\mathrm{c}^{\mathrm{E}}\right] \mathrm{k}^{3} \mathrm{dk} /\left[\mathrm{c}^{\mathrm{E}}\right] \mathrm{k}^{3} \mathrm{dk}\right) \times 100$ where $\mathrm{c}^{\mathrm{T}}$ and $\mathrm{c}^{\mathrm{E}}$ are the theoretical and experimental EXAFS and $\mathrm{k}$ is the photoelectron wave vector.

Other parameters: $\mathrm{AFAC}=0.9$, related to the proportion of electron undergoing scattering post absorption that contribute to the EXAFS. The fitting range is $2.5-13.5 \mathrm{k}\left(\AA^{-1}\right)$. 


\section{Figure 1}

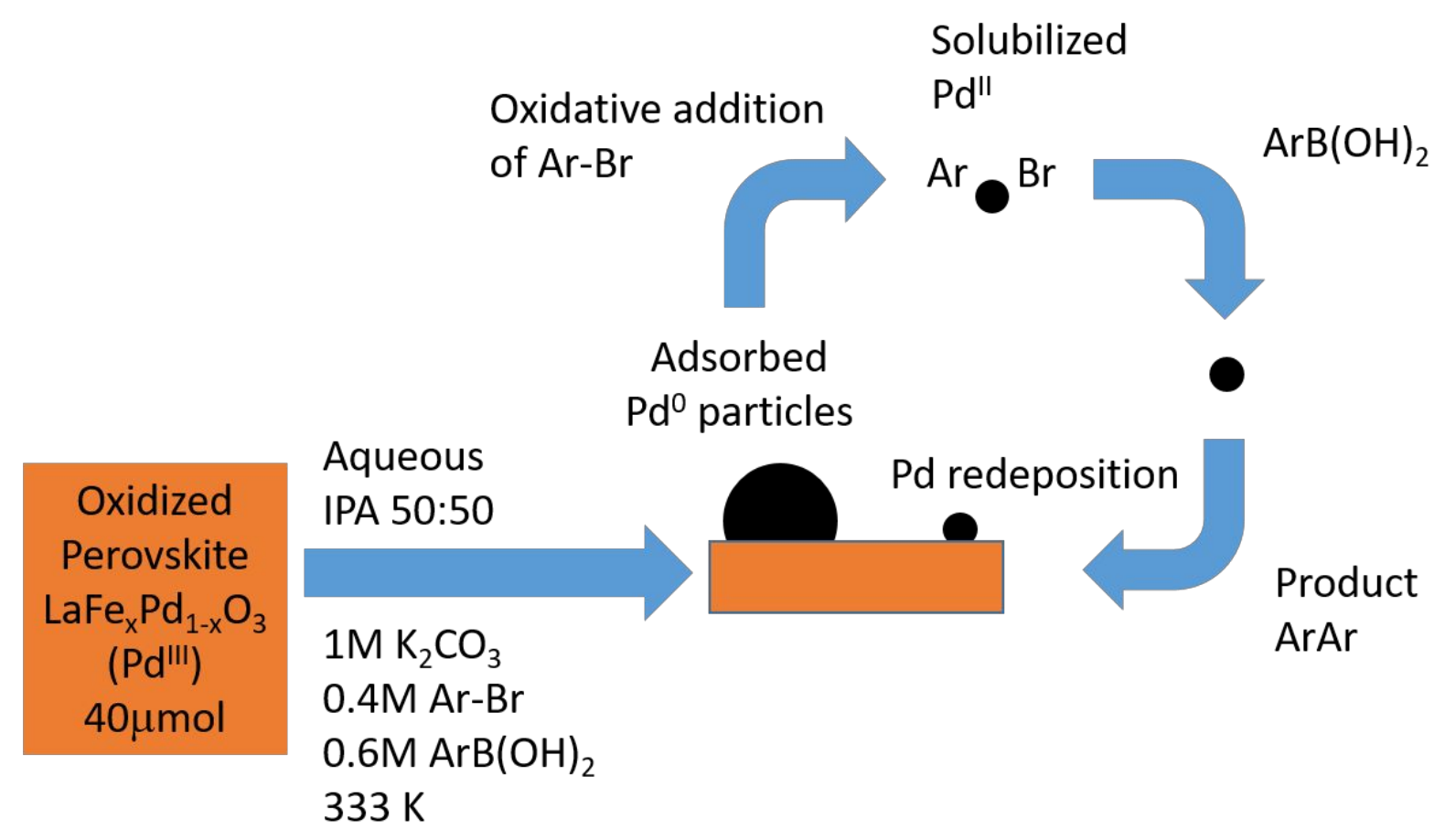


Figure 2
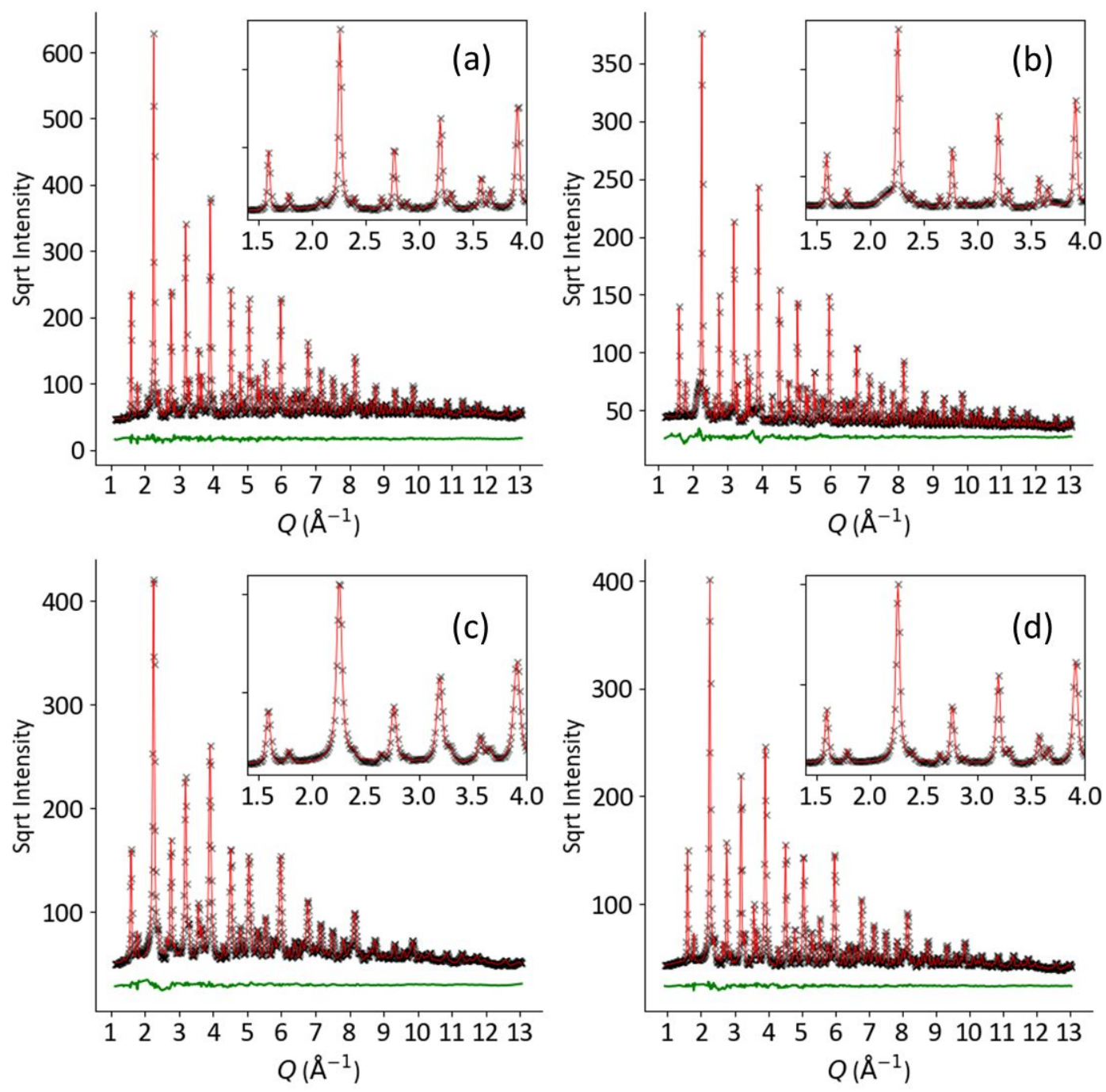
Figure 3

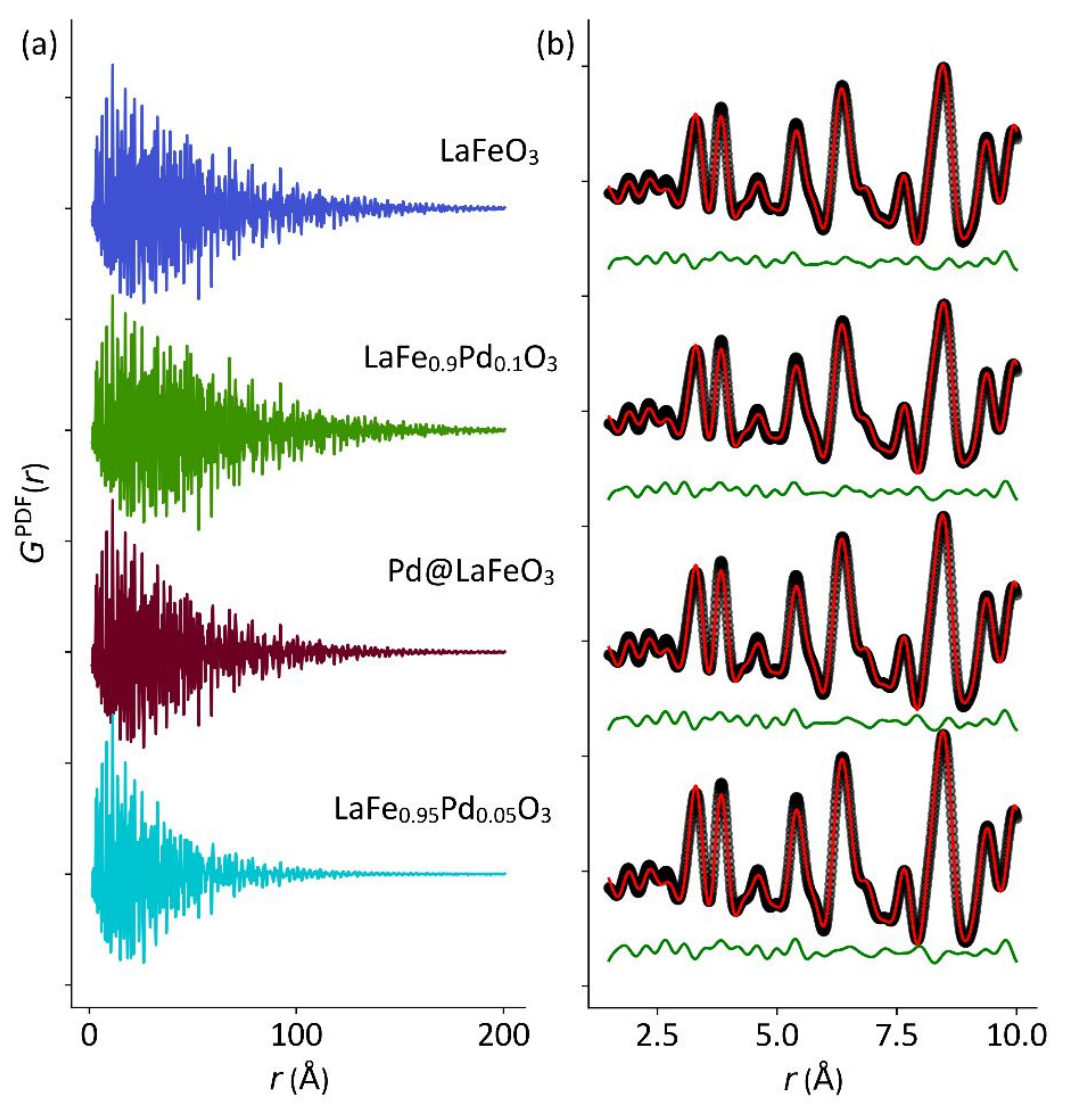




\section{Figure 4}

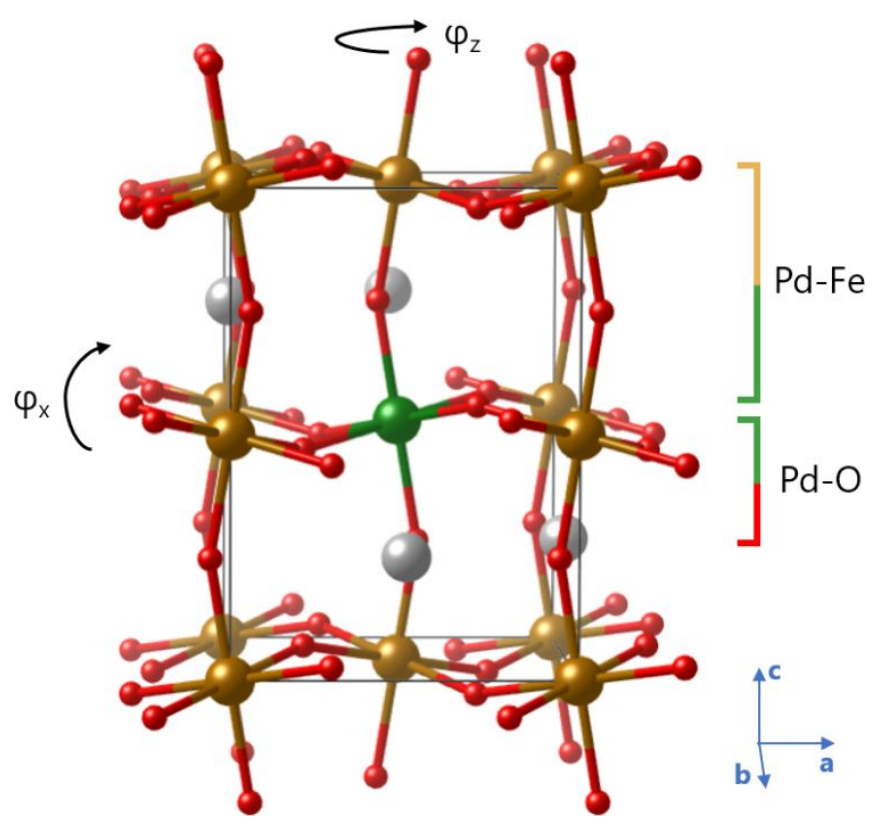


Figure 5

(a)

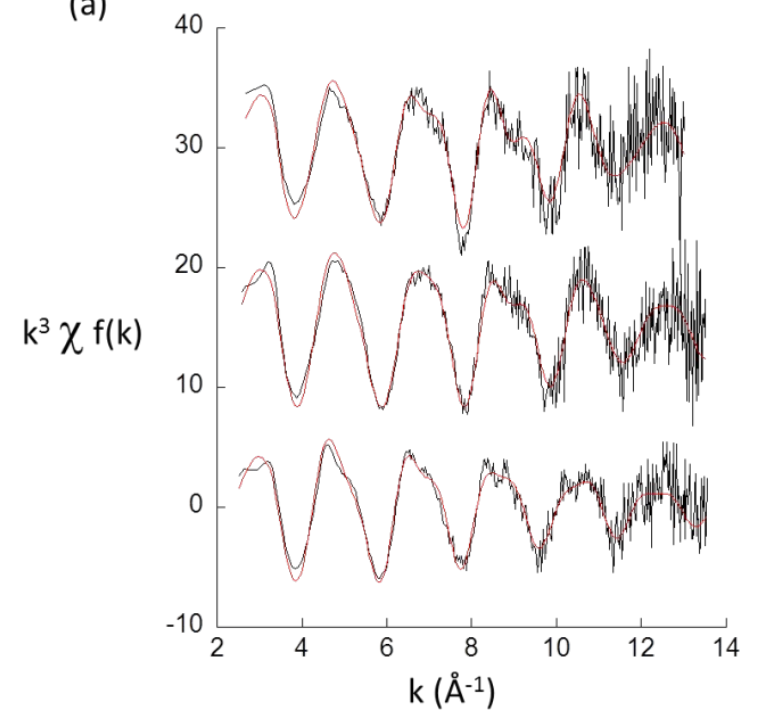

(b)

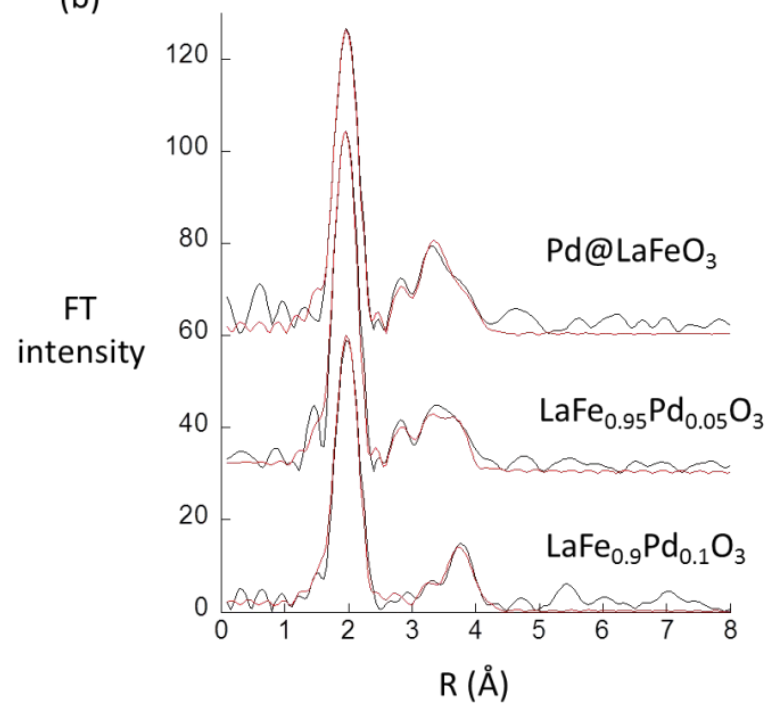

10

11

12

13

14

15

16

17

18

19

20

21

22

23

24

26

27

28

29

30

31

32

33

34

35

36

37

38

39

40

41

42

43

44

45

46

47

48

49

50

51

52

53

54

55

56

57

58

59

60 


\section{Figure 6}

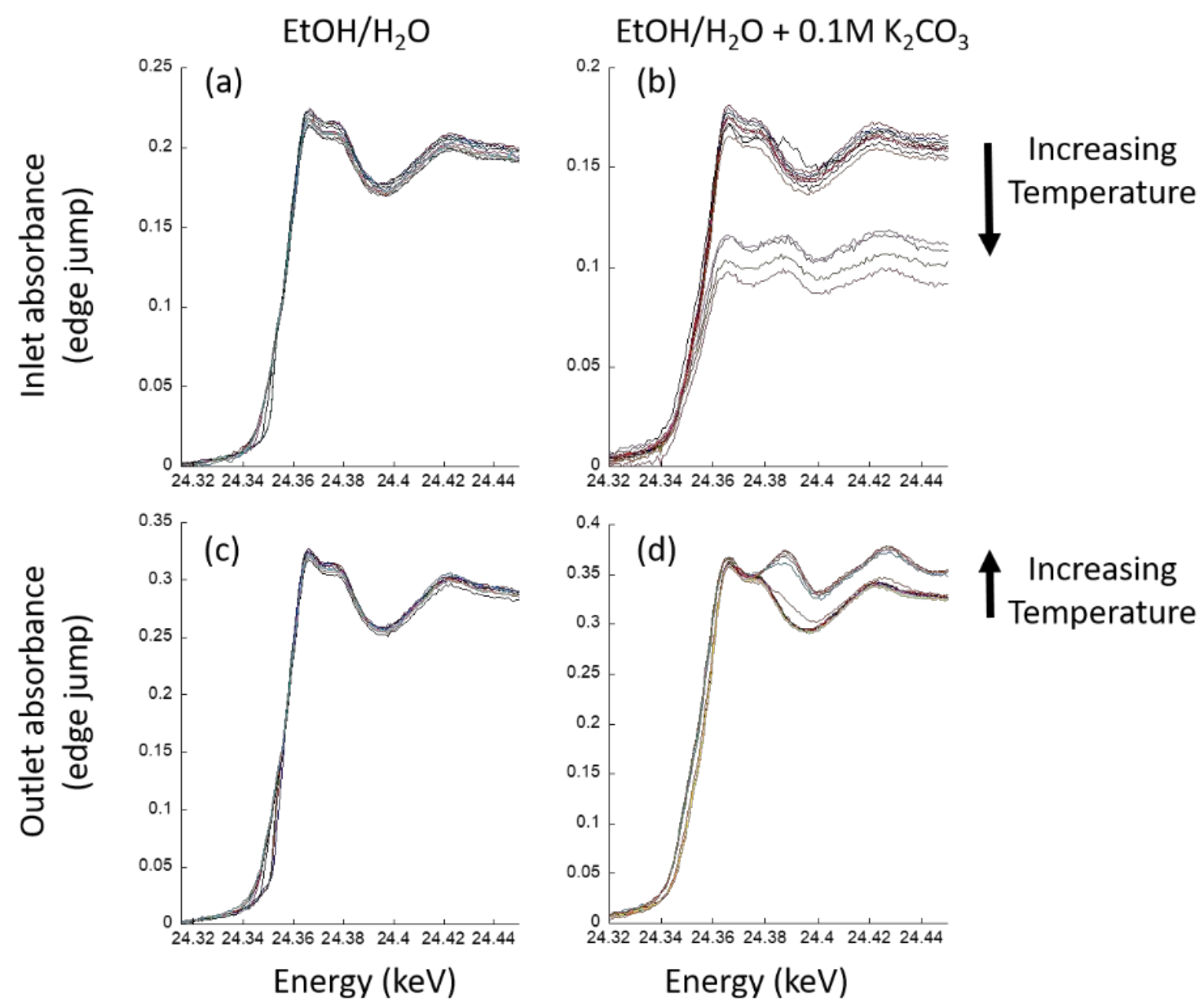


Figure 7

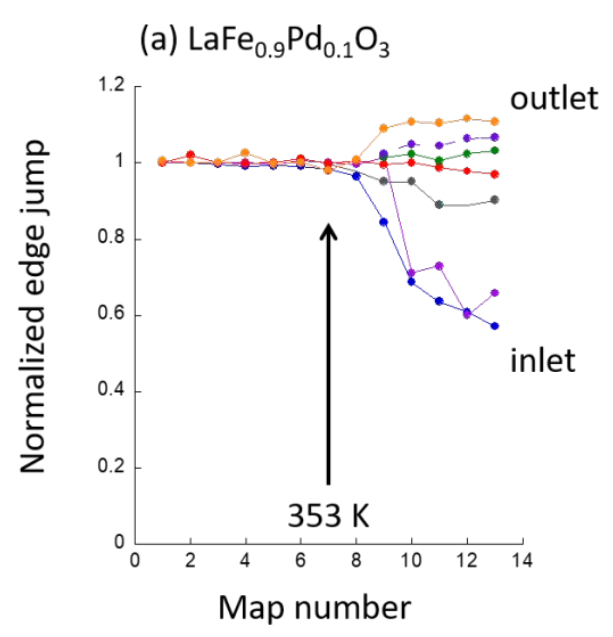

(b) $\mathrm{LaFe}_{0.95} \mathrm{Pd}_{0.05} \mathrm{O}_{3}$

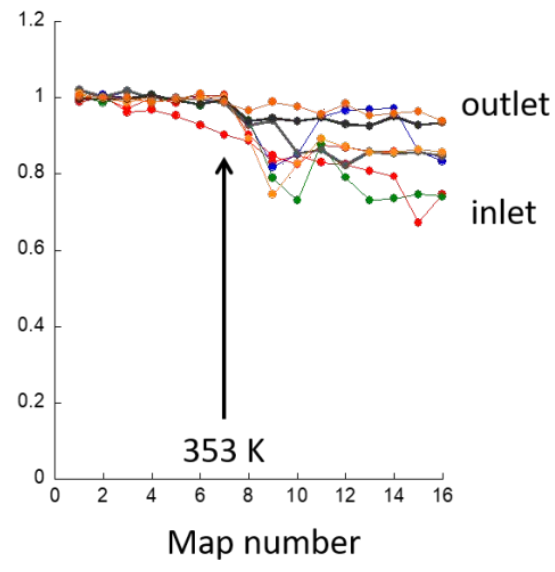

(c) Pd@ @aFeO 3

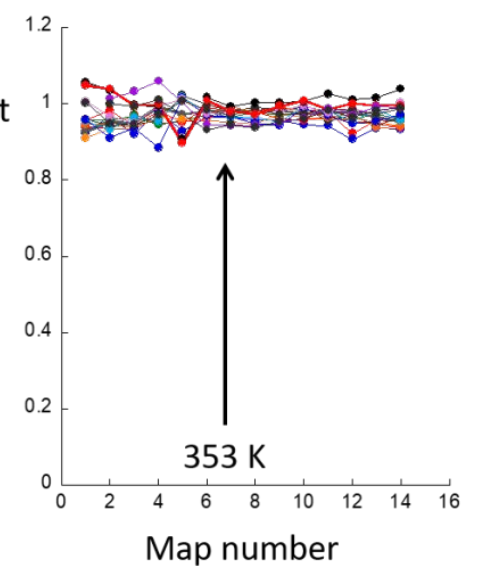




\section{Figure 8}
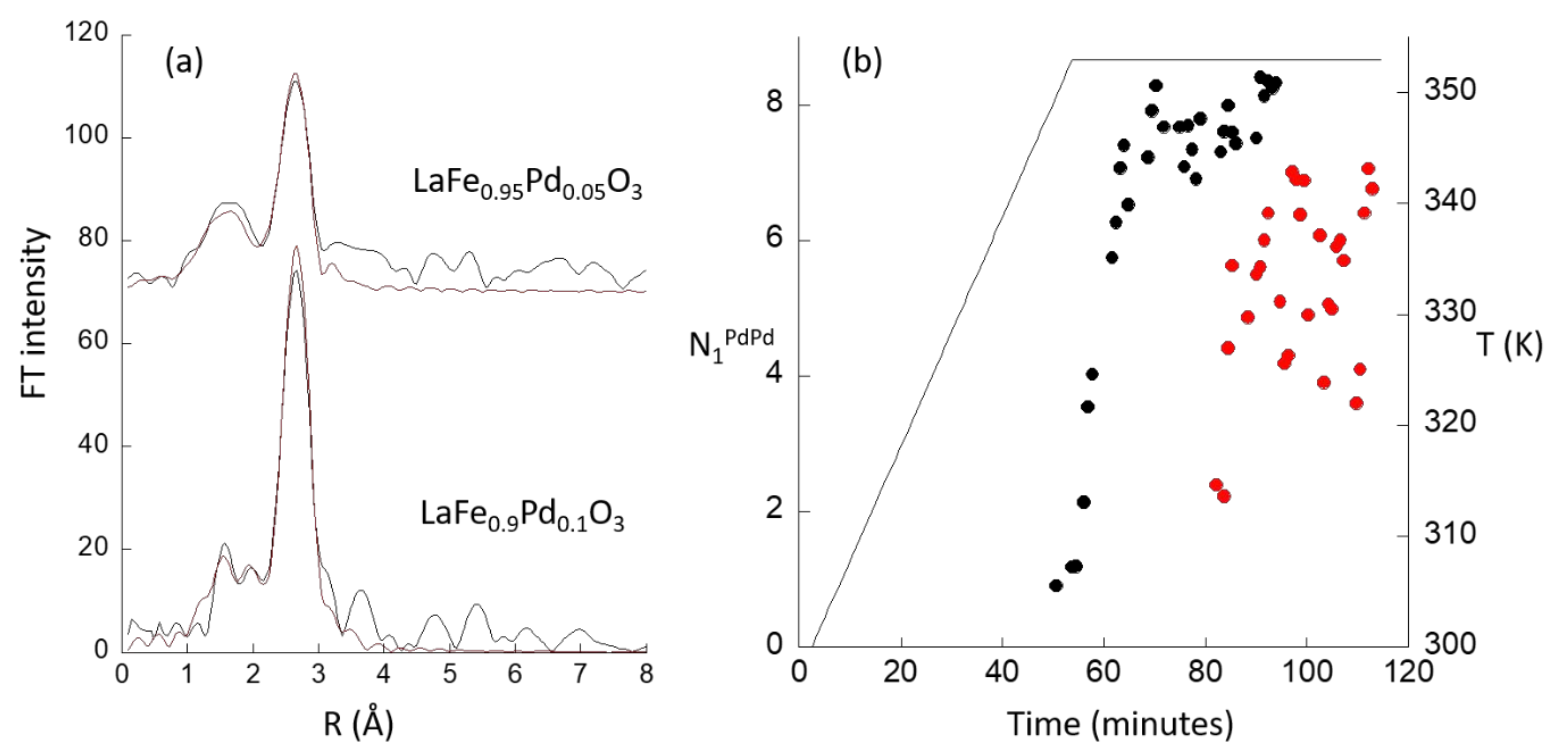


\section{Figure 9}
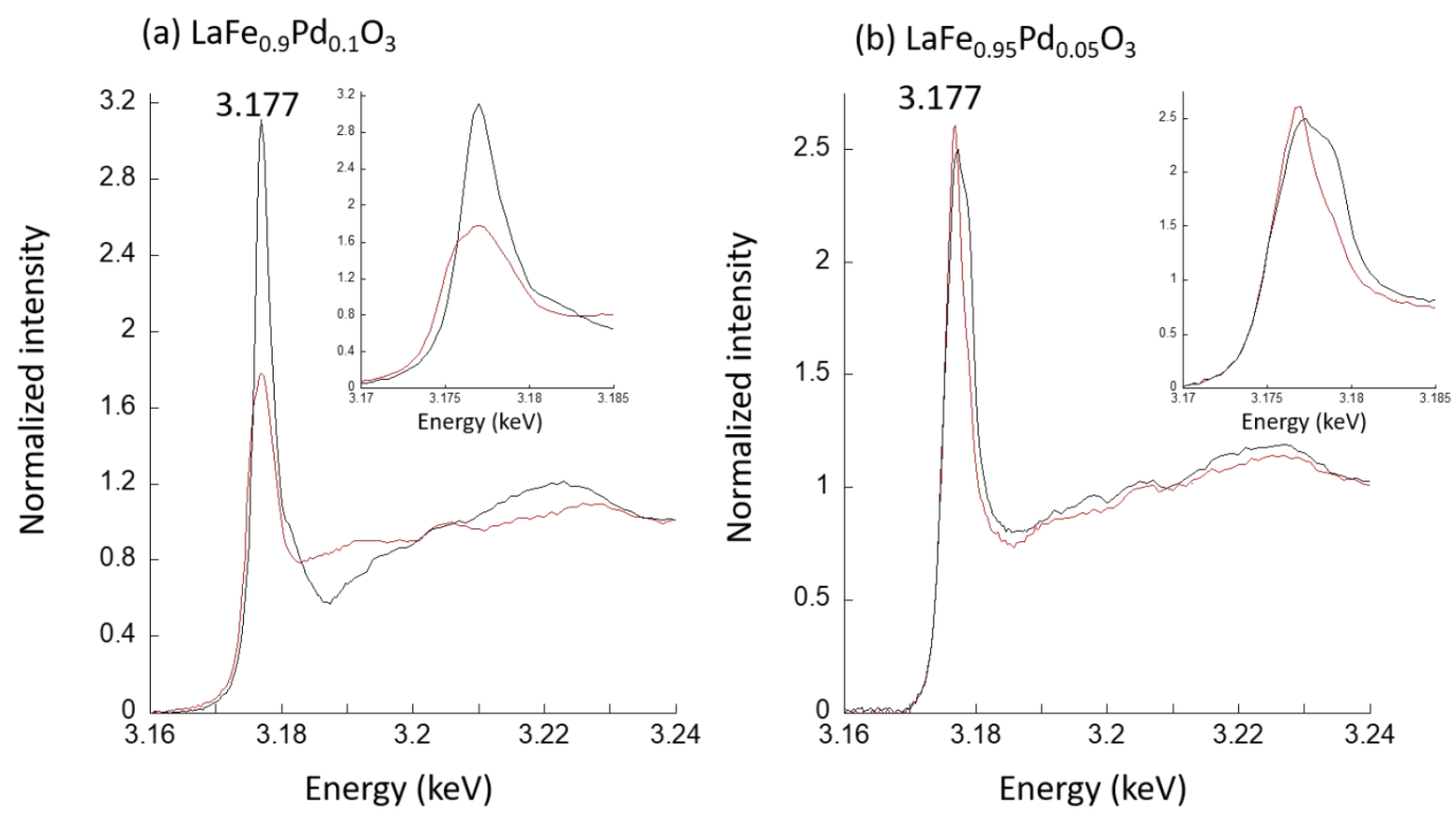


\section{Figure 10}
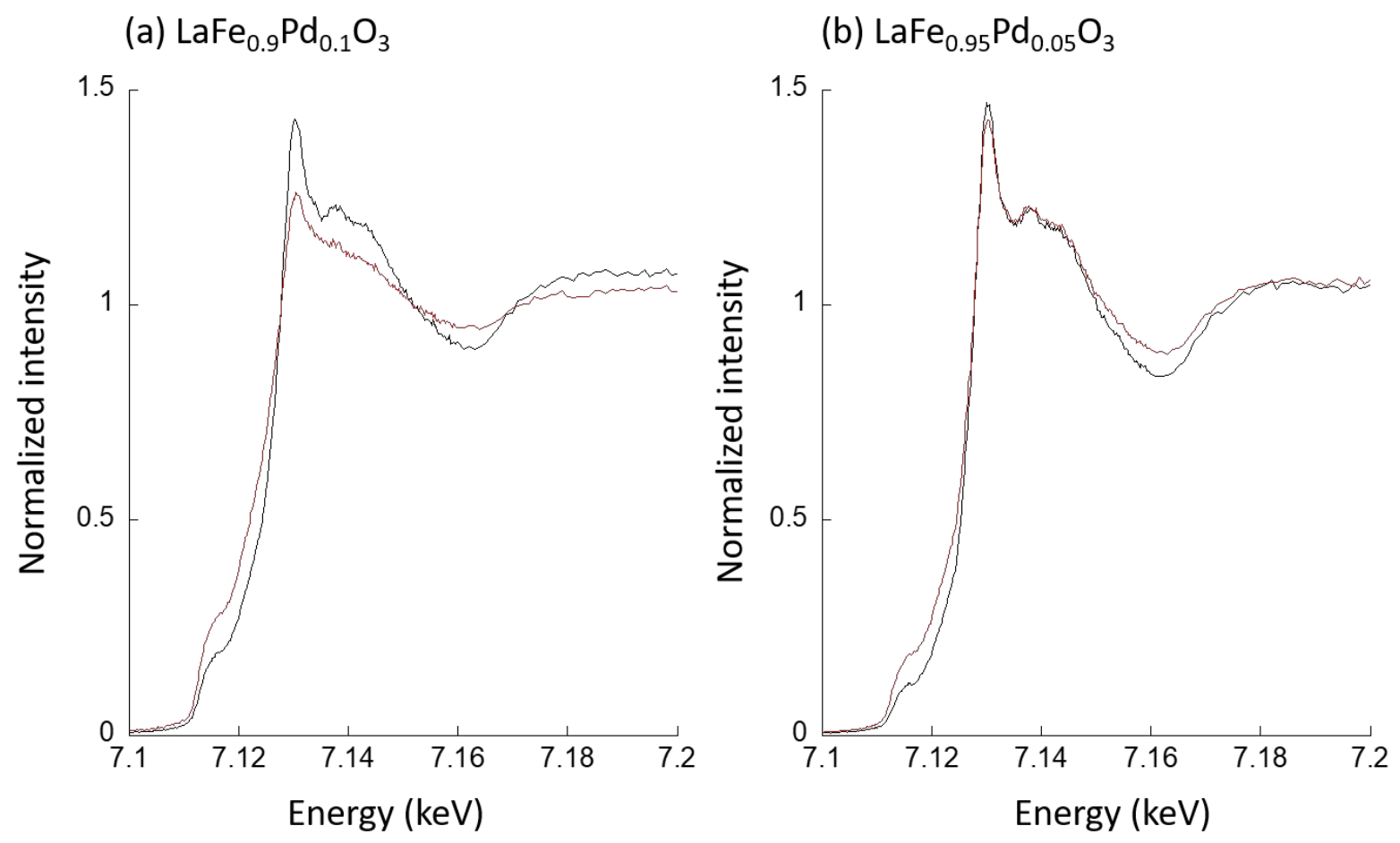
Figure 11
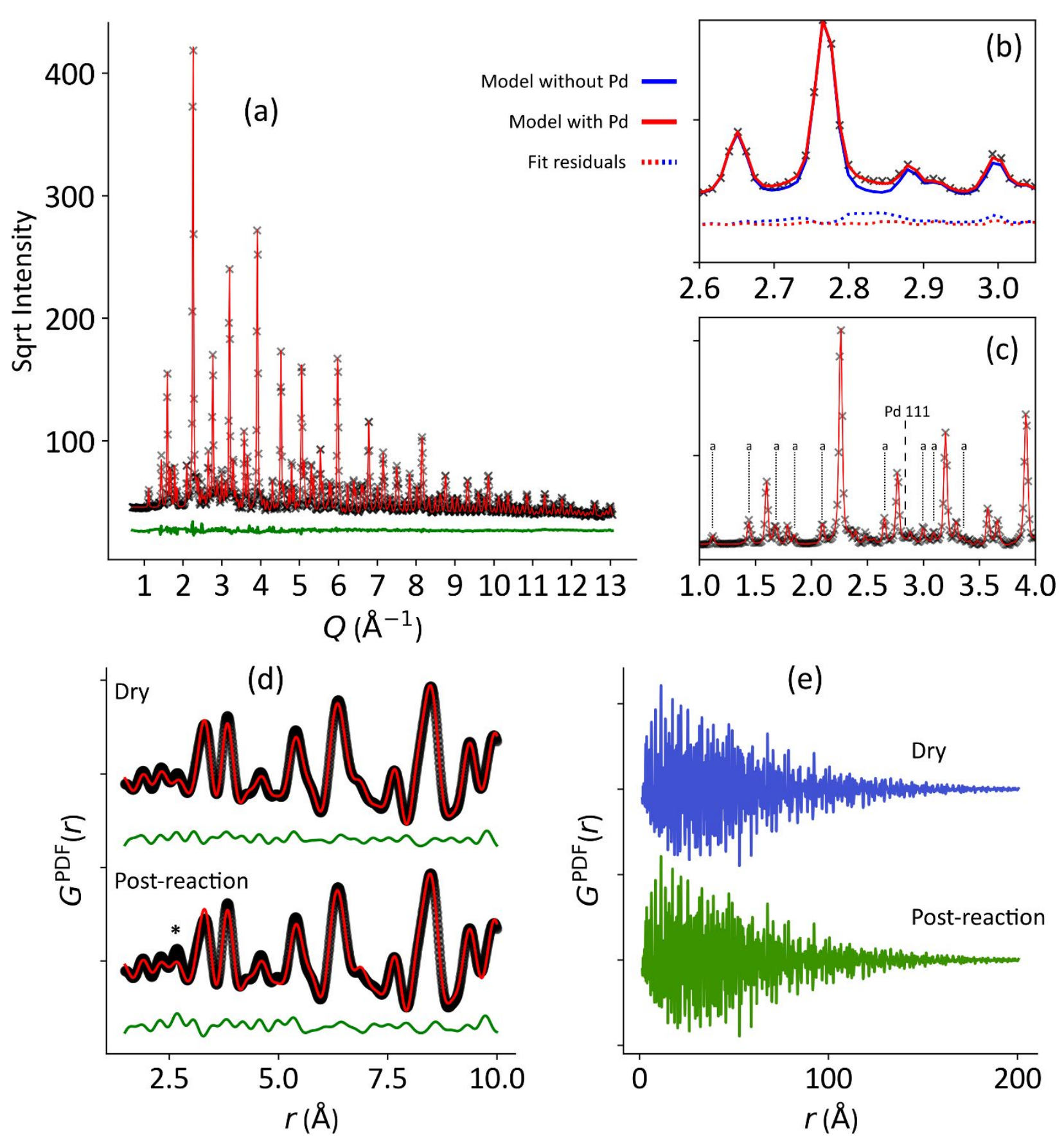
Figure 1. Schematic representation of the steps involved in the Suzuki reaction catalysed by $\mathrm{LaFe}(\mathrm{Co}) \times \mathrm{Pd}(1-$ x)O3 as concluded by Andrews et al.8 Initially oxidised Pd held within the perovskite structure must be reduced and presented to the reaction mixture at the catalyst surface whereupon it is solubilised to yield the catalytically active site. This solubilised $\mathrm{Pd}$ is then redeposited on the perovskite post reaction.

$$
201 \times 121 \mathrm{~mm}(150 \times 150 \mathrm{DPI})
$$



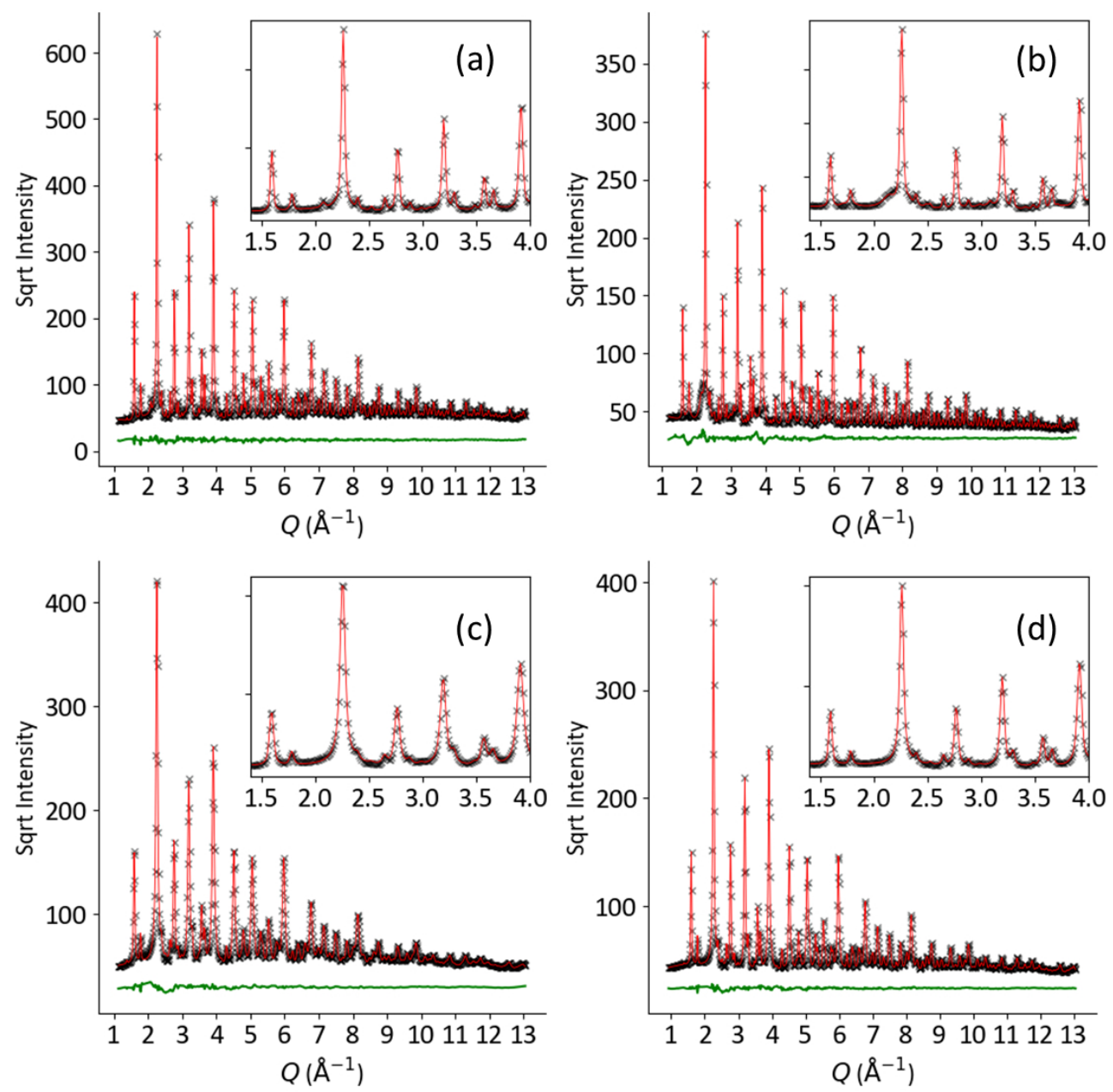

General model of the orthorhombic Pbnm structure found for the different perovskite samples measured in this work. The unit cell atoms are: La $(4 c, \sim 0, \sim 0.5,0.25)$ (grey); Fe/Pd $(4 a, 0,0,0)$ (atoms with mixed occupancy in gold, emphasized Pd atom in green); 01 (4c, 0, 0, 0.25) (red); O2 (8d, 0.25-u, 0.25+v, w) (red).

The first-neighbour Pd-O and Pd-Fe distances are indicated by the brackets. The tilt angles $\varphi x$ and $\varphi z$ are calculated, respectively, as $\tan -1(2 u+2 v)$ and $\tan -1(4 \sqrt{ } 2 w) .53$

$191 \times 190 \mathrm{~mm}(150 \times 150 \mathrm{DPI})$ 

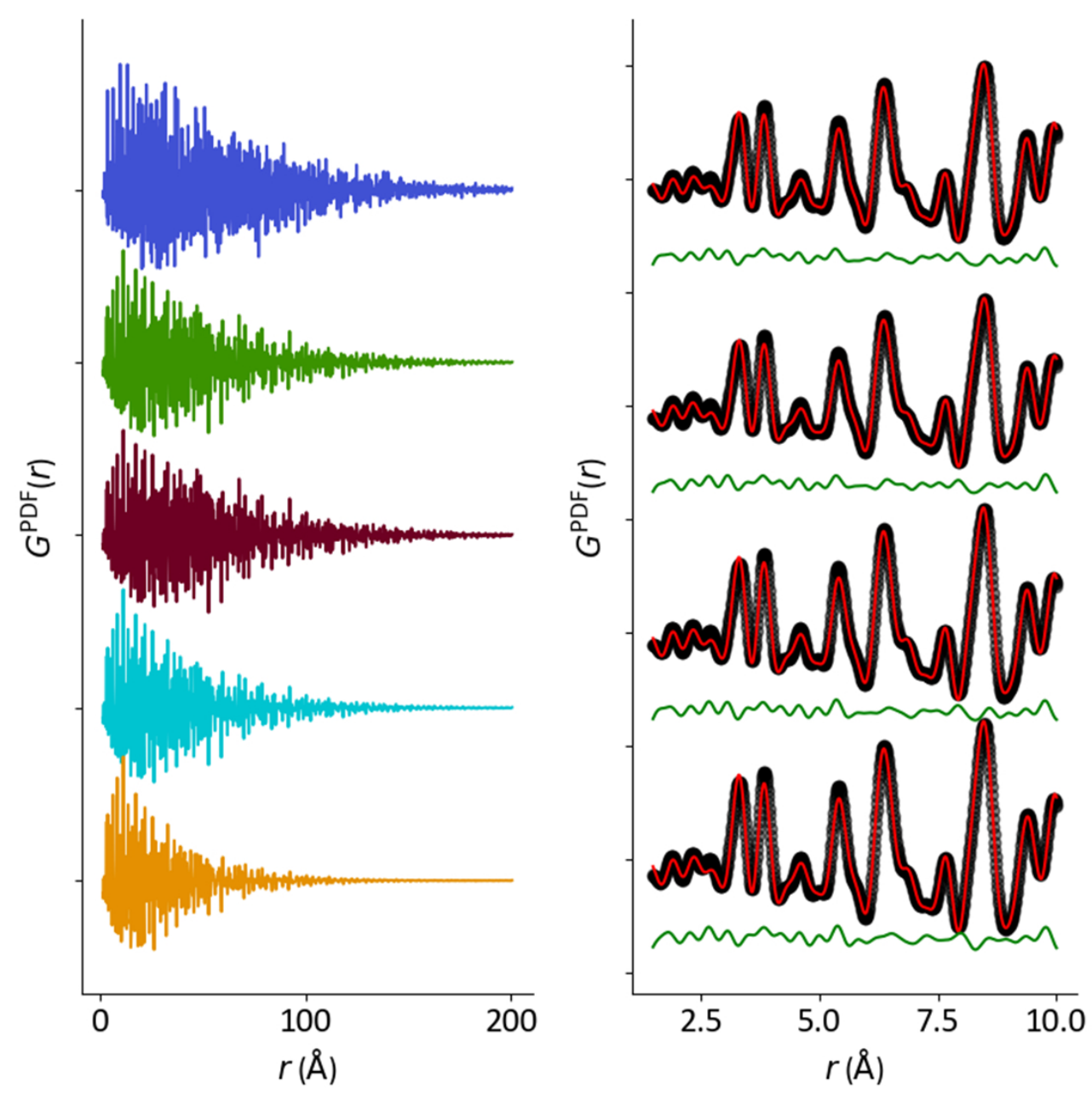

PDF of the samples in their as received states along with the PDF due to the $\mathrm{CeO} 2$ reference material. (a) Complete $G(r)$ envelopes from 0 to $200 \AA$; (b) Close up of the $G(r$ in the 1.5 to $10 \AA$ range, for the four perovskite samples, along with fits to the data (red) and residuals (green).

$$
\text { 189x190mm ( } 150 \times 150 \text { DPI) }
$$




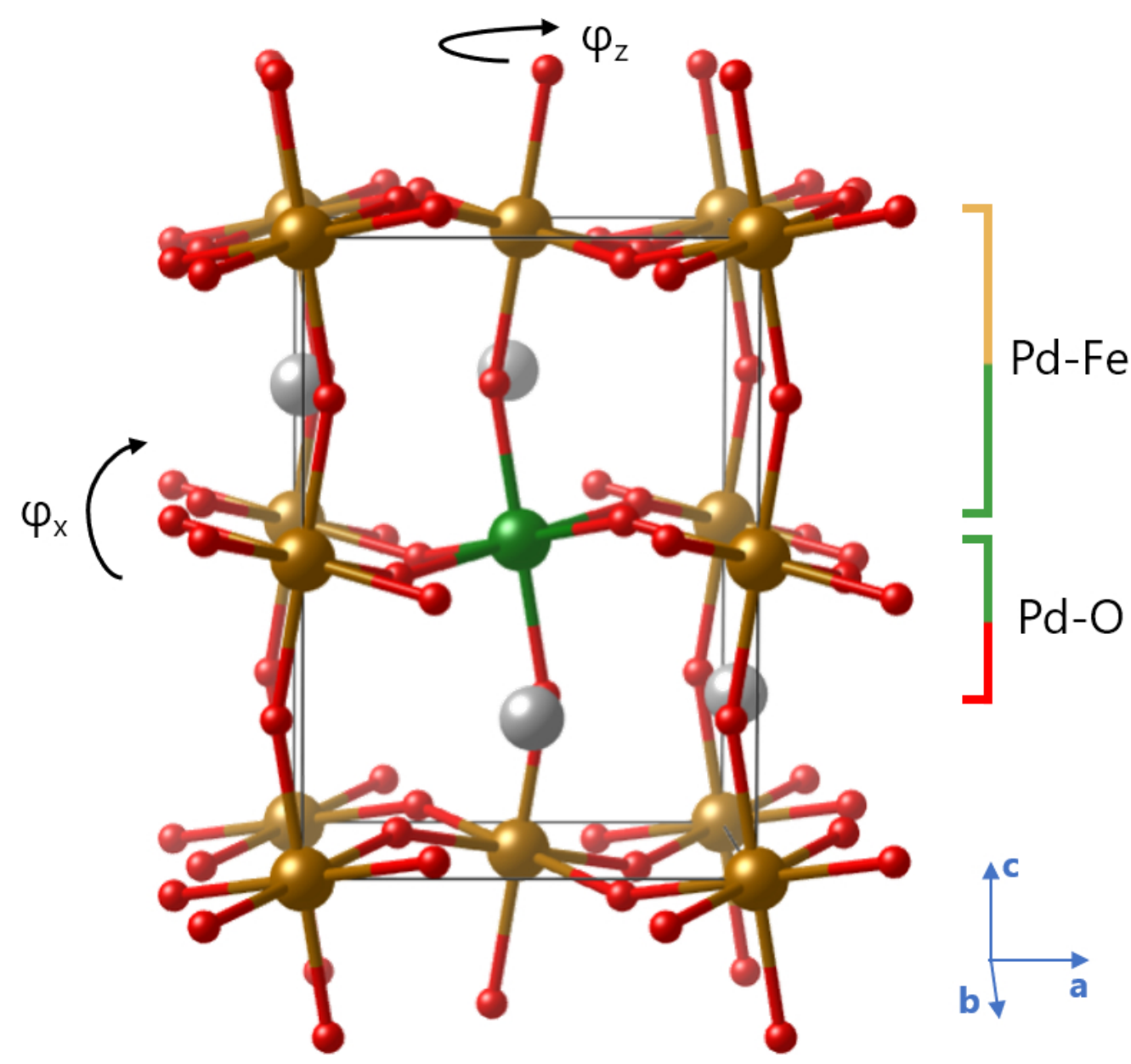

General model of the orthorhombic Pbnm structure found for the different perovskite samples measured in this work. The unit cell atoms are: La $(4 c, \sim 0, \sim 0.5,0.25)$ (grey); Fe/Pd $(4 a, 0,0,0)$ (atoms with mixed occupancy in gold, emphasized Pd atom in green); 01 (4c, 0, 0, 0.25) (red); $02(8 d, 0.25-u, 0.25+v, w)$ (red).

$130 \times 122 \mathrm{~mm}(150 \times 150 \mathrm{DPI})$ 


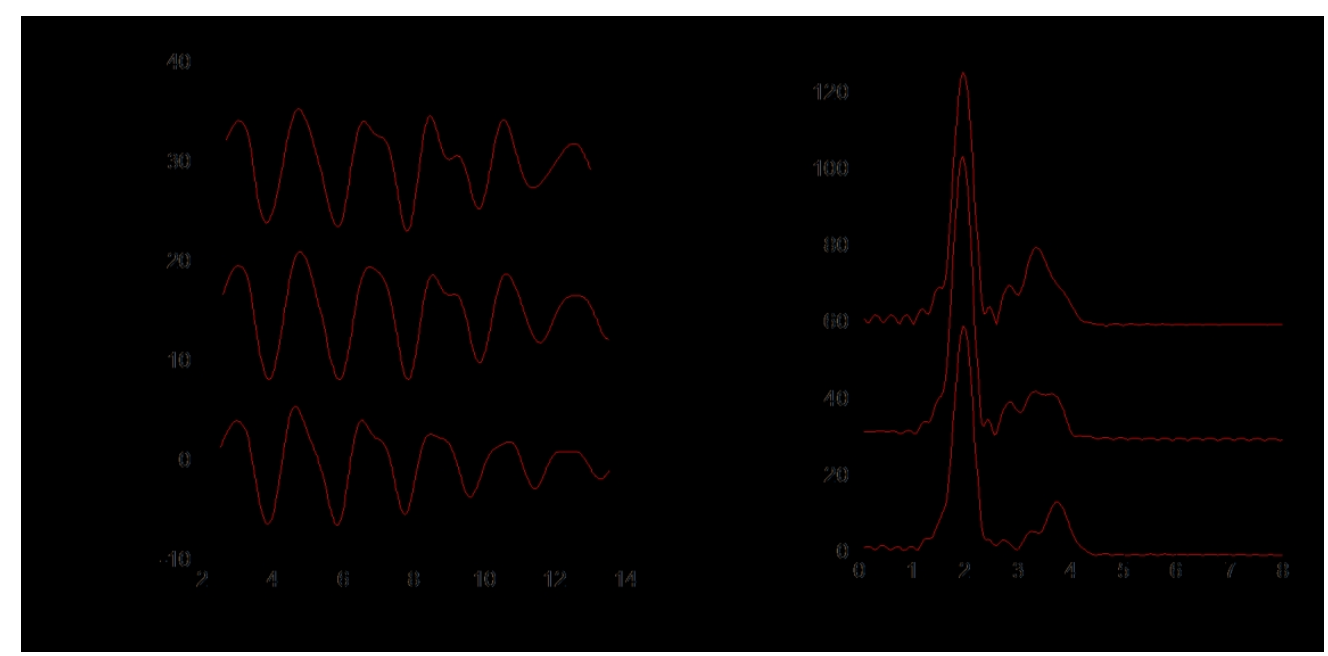

Pd K-edge EXAFS obtained from the three catalysts studied in their dry state. (a) k3-weighted EXAFS; (b) Fourier transforms of the k3-weighted EXAFS. The red lines are the fits arising from analysis in EXCURV.40 $276 \times 135 \mathrm{~mm}(150 \times 150 \mathrm{DPI})$ 
Background subtracted Pd K-edge XANES spectra of LaFe0.9Pd0.103 system collected at the reactor inlet and reactor outlet under heating in ethanol/water ((a) and (c)) and under ethanol/water/K2CO3 ((b) and (d)). The arrows indicate the direction of the changes with increasing temperature.

$214 \times 180 \mathrm{~mm}(150 \times 150 \mathrm{DPI})$ 


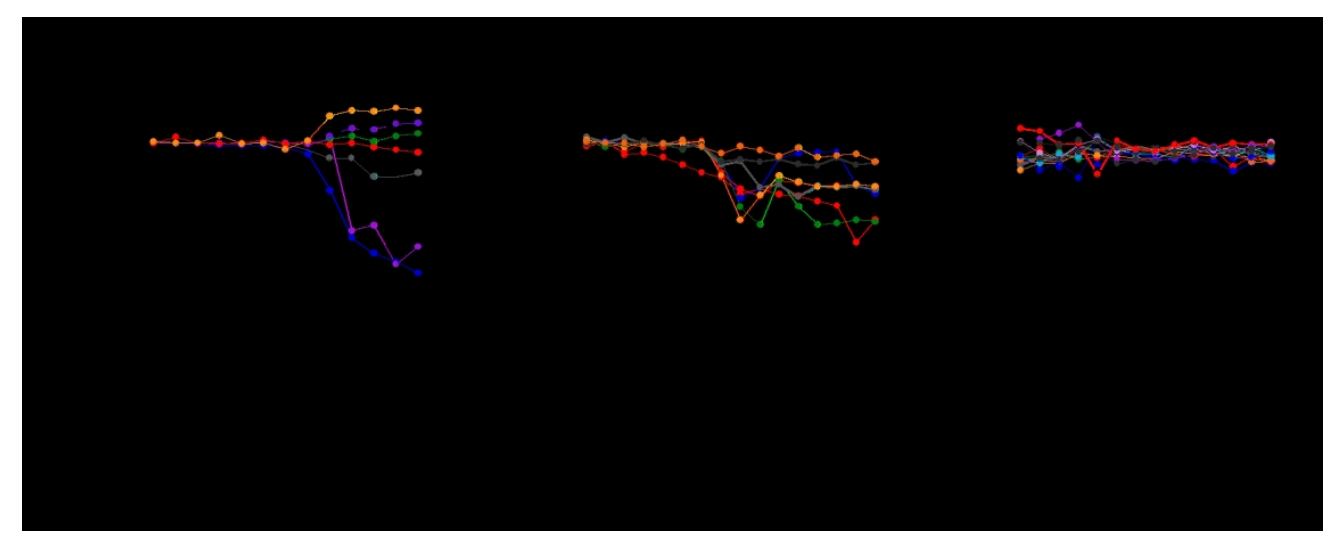

Variation in Pd K-edge jump of: (a) LaFe0.9Pd0.1 O3; (b) LaFe0.95Pd0.05O3; and (c) Pd@ LaFeO3 during heating to $353 \mathrm{~K}$ and dwelling in ethanol/water/K2CO3. In each case the Pd K-edge jump has been normalised to the value obtained at each axial position in the bed once the sample has been made wet in the ethanol/water/K2CO3 at room temperature.

$284 \times 112 \mathrm{~mm}(150 \times 150 \mathrm{DPI})$ 
(a) Fourier transforms of the k3-weighted Pd K-edge EXAFS derived from the outlet of beds comprised of LaFe0.9Pd0.103 and LaFe0.95Pd0.0503, at $353 \mathrm{~K}$. The red lines are fits to the data. (b) Evolution of the coordination number of the Pd-Pd first neighbour (N1PdPd), as a function of time and temperature for

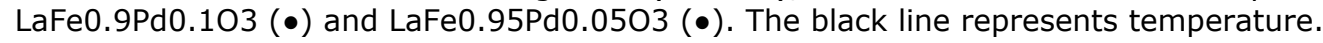

$269 \times 130 \mathrm{~mm}(150 \times 150 \mathrm{DPI})$ 


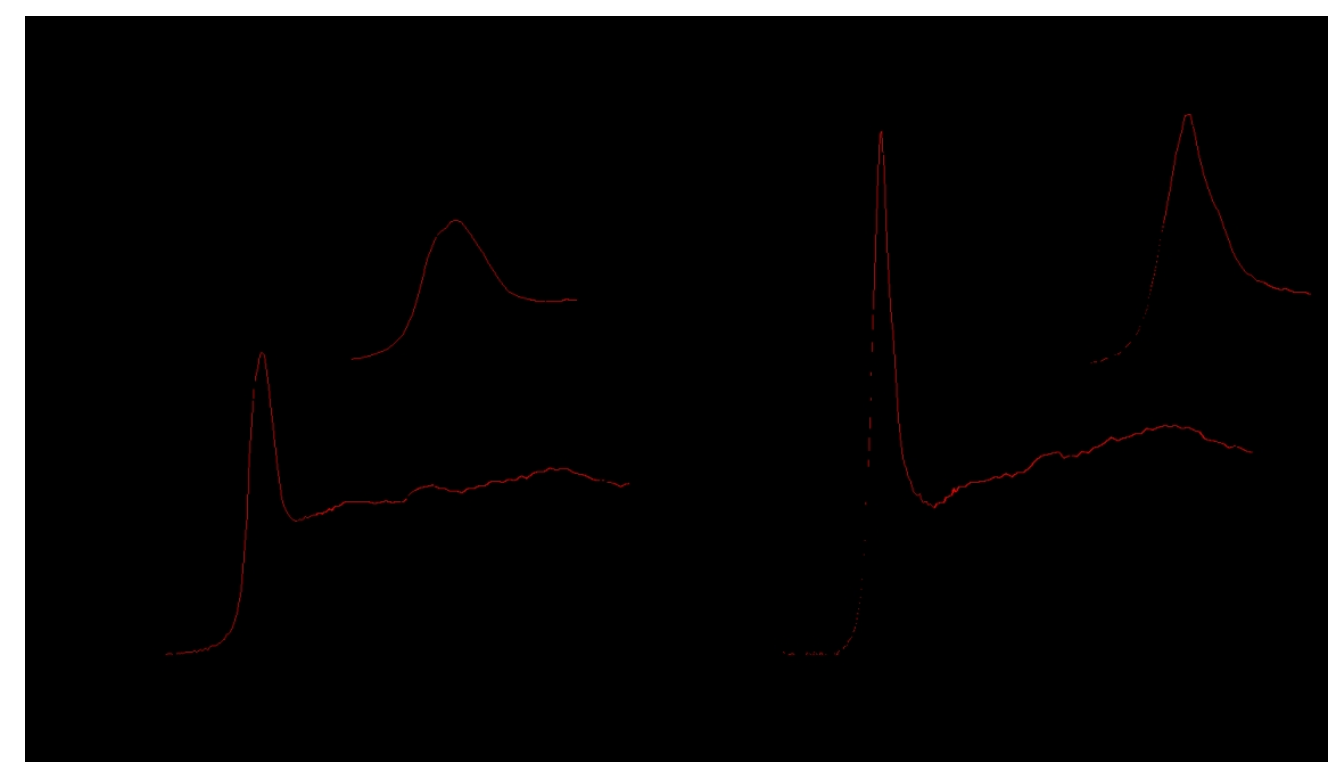

Pd L3-edge XANES of (a) LaFe0.9Pd0.103 and (b) LaFe0.95Pd0.05O3 in their dry state (black) and post reaction with ethanol/water/K2CO3 (red). The inset shows expanded views of the white line regions of the spectra.

$249 \times 142 \mathrm{~mm}(150 \times 150 \mathrm{DPI})$ 


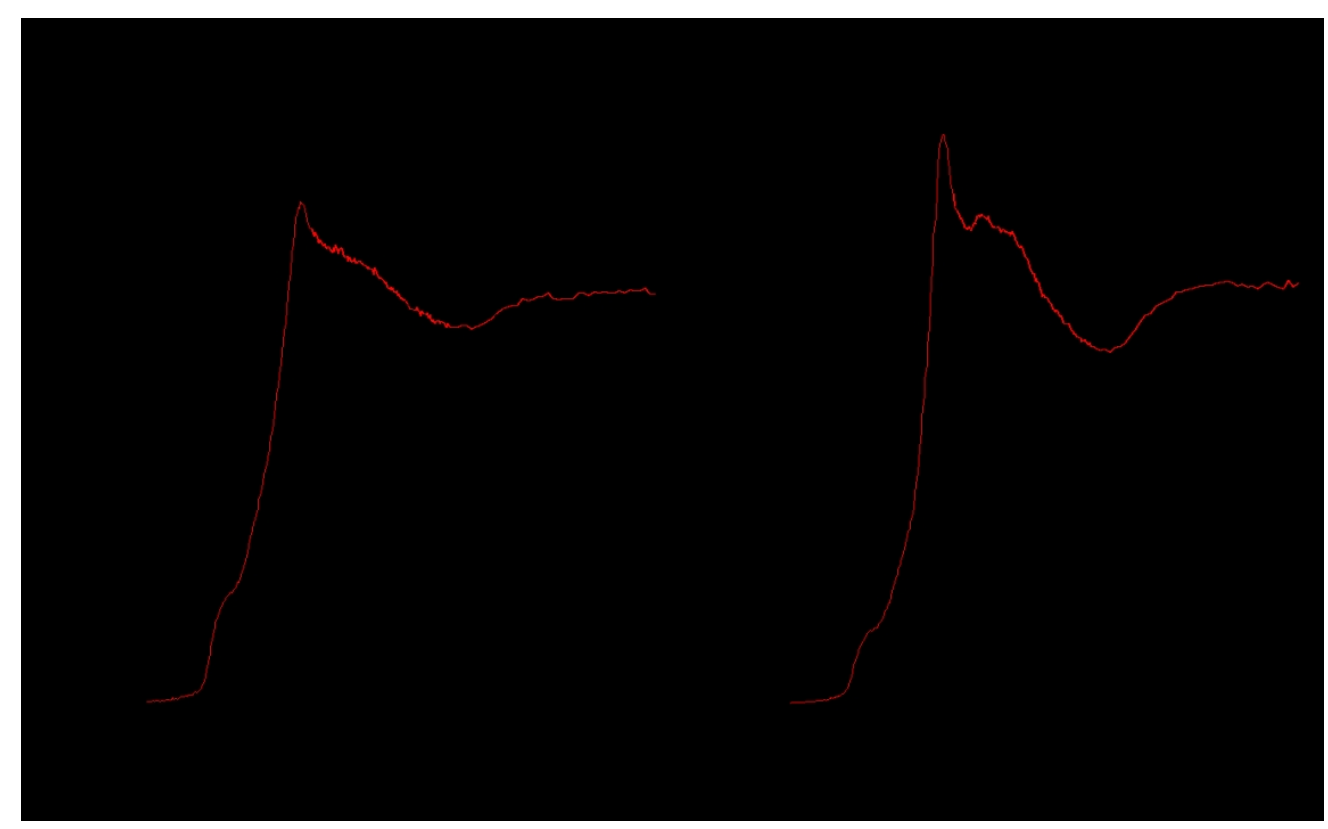

Fluorescence yield Fe K-edge XANES of (a) LaFe0.9Pd0.103 and (b) LaFe0.95Pd0.05O3 from both dry samples (black) and after reaction in flowing $\mathrm{EtOH} / \mathrm{H} 2 \mathrm{O}+\mathrm{K} 2 \mathrm{CO} 3$ (red).

$230 \times 141 \mathrm{~mm}(150 \times 150 \mathrm{DPI})$ 

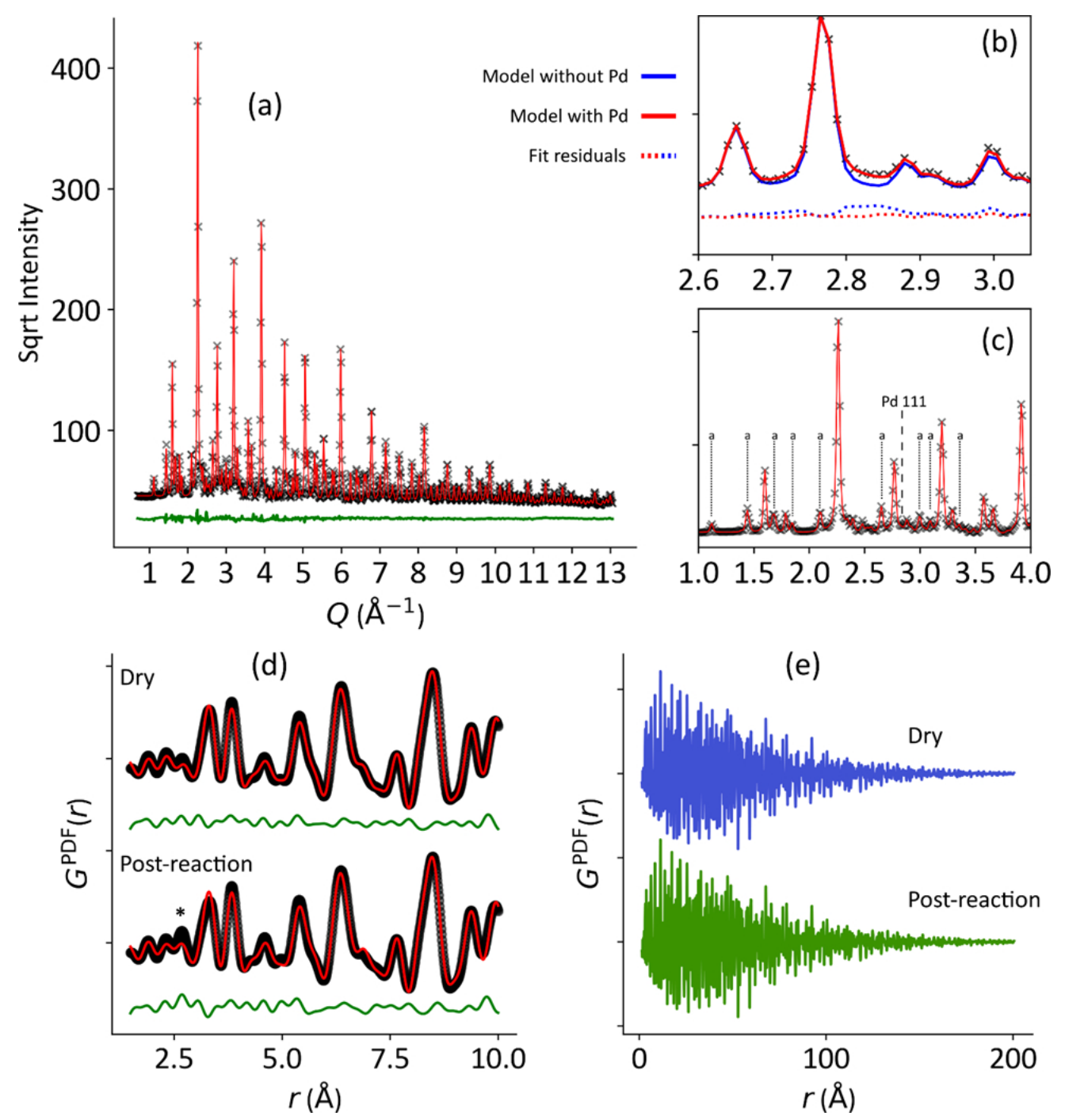

(a) HXRD pattern of LaFe0.9Pd0.103 after reaction in flowing EtOH/H2O + K2CO3. (b) Comparison of the Rietveld refinements including the $\mathrm{Pd}$ phase and without in the region around the Pd 111 reflection. (c) Close-up view of the low-Q range; dotted lines indicate peaks belonging to the $\mathrm{La} 2(\mathrm{CO} 3) 2(\mathrm{OH}) 2 \mathrm{phase}$ and a dashed line points to the Pd 111 reflection. (d) The PDF curves of LaFe0.9Pd0.103 before reaction (top) and after reaction(bottom) fitted in the range $r \leq 10 \AA$ with the Pbnm orthorhombic model; black symbols are the experimental data, red lines the calculated PDF, green lines the fit residual; an asterisk indicates the position of the Pd-Pd first-neighbour distance. (e) The full-range PDF curves of LaFe0.9Pd0.103 before reaction (top) and after reaction (bottom).

$$
165 \times 175 \mathrm{~mm}(150 \times 150 \mathrm{DPI})
$$


No reaction

\section{Page 57 of 57}
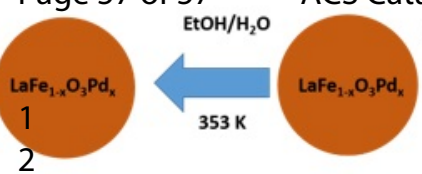

3

4

5

6

7

$\mathrm{EtOH} / \mathrm{H}_{2} \mathrm{O}$

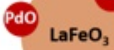

Reduction and segregation of Pd then leaching

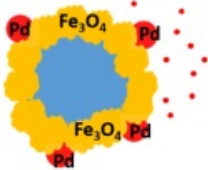

Segregation and reduction of $\mathrm{Fe}$
$353 \mathrm{~K}$

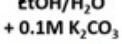

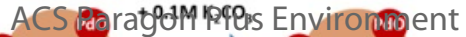

PdO
PdO

$\mathrm{LaFeO}_{3}$

$353 \mathrm{~K}$
No

reaction 